\title{
Demonstration of carbon catabolite repression in naphthalene degrading soil bacteria via Raman spectroscopy based stable isotope probing
}

\author{
Vinay Kumar B.N. ${ }^{\mathbf{a b}}$, Shuxia Guo ${ }^{\mathbf{a}, \mathbf{c}}$, Thomas Bocklitz ${ }^{\mathbf{a}, \mathbf{b}, \mathbf{c}}$, Petra Rösch ${ }^{\mathbf{a}, \mathbf{b}}$ and Jürgen Popp*a, a,b,c

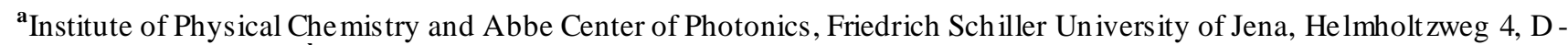 \\ 07743 Jena, Germany, ${ }^{\mathbf{b}}$ Infecto Gnostics, Forschungscampus Jena, Philosophenweg 7, D-07743 Jena, Germany, ${ }^{\mathbf{c}}$ Leibniz \\ Institute of Photonic Technology, Albert-Einstein-Straße 9, D-07745 Jena, Germany
}

Author information

E-mail: juergen.popp@uni-jena.de; Fax: +49-3641-948302; Tel: +49-3641-948320,+49-3641-206300

Table of contents - Sample preparation, Raman instrumentation and data processing

Figure S1. Mean spectra of $N$. aromaticivorans cultured under different ${ }^{13} \mathrm{C}$ labeled carbon sources

Figure S2. Mean spectra of $C$. basilensis cultured under different ${ }^{13} \mathrm{C}$ labeled carbon sources

Figure S3. Mean spectra of $R$. opacus cultured under increasing percentage of ${ }^{13} \mathrm{C}$ glucose

Figure S4. Growth curves of the three species of bacteria R. opacus, N. aromaticivorans and C. basilensis

Figure S5. Raman spectral correlation and confusion matrix of $R$. opacus

Figure S6. Raman spectral correlation and confusion matrix of N. aromaticivorans

Figure S7. Raman spectral correlation and confusion matrix of C. basilensis

Figure S8. Mean spectra of $R$. opacus cultured under increas ing percentage of ${ }^{2} \mathrm{H}$ glucose

Figure S9: Time dependent and 2D Raman correlation spectra of $R$. opacus cultured with a combination of ${ }^{2} \mathrm{H}$ glucose and ${ }^{13} \mathrm{C}$ fructose as carbon sources

Figure S10. Time dependent and 2D Raman correlation spectra of $R$. opacus cultured with a combination of ${ }^{2} \mathrm{H}$ glucose and ${ }^{13} \mathrm{C}$ naphthalene as carbon sources

Figure S11.Time dependent and 2D Raman correlation spectra of $N$. aromaticivorans cultured with a combination of ${ }^{2} \mathrm{H}$ glucose and ${ }^{13} \mathrm{C}$ galactose as carbon sources

Figure S12. Time dependent and 2D Raman correlation spectra of $N$. aromaticivorans cultured with a combination of ${ }^{2} \mathrm{H}$ glucose and ${ }^{13} \mathrm{C}$ fructose as carbon sources

Figure S13. Time dependent and 2D Raman correlation spectra of $N$. aromaticivorans cultured with a combination of ${ }^{2} \mathrm{H}$ glucose and ${ }^{13} \mathrm{C}$ naphthalene as carbon sources 
Figure S14. Time dependent and 2D Raman correlation spectra of C. basilensis cultured with a combination of ${ }^{2} \mathrm{H}$ glucose and ${ }^{13} \mathrm{C}$ galactose as carbon sources

Figure S15. Time dependent and 2D Raman correlation spectra of C. basilensis cultured with a combination of ${ }^{2} \mathrm{H}$ glucose and ${ }^{13} \mathrm{C}$ fructose as carbon sources 


\section{Sample preparation and data processing}

Single labeling experiment: Two to three colonies from the individual culture plates of the respective bacteria under study was inoculated into M9MM liquid media (Sigma-Aldrich) consisting of a sole carbon source of either universally ${ }^{13} \mathrm{C}$ labeled glucose, fructose, galactose in final concentrations of $32 \mathrm{mM}$ (Cambridge Isotope Lab Inc) or consisting of naphthalene in final concentration of $22 \mathrm{mM}$ (Sigma-Aldrich). These cultures were then incubated for 3 to 5 days depending on the species, 3 days for $R$. opacus and $N$. aromaticivorans and 5 days for C. basilensis. Post incubation, sample is suspended in distilled water contained in a $1500 \mu l$ Eppendorf vial. The cells are washed twice using distilled water by centrifuging the samples at 12,500 rpm for 3 min to remove any residual media which would hinder the Raman spectral signatures. The pellet thus obtained is again suspended into distilled water and vortexed vigorously at $2500 \mathrm{rpm}$ for $2 \mathrm{~min}$ in order to achieve separation of the cluster of cells so as to be able to analy ze single cells. $5 \mu \mathrm{l}$ of the sample thus obtained is now transferred to a nickel foil and allowed to air dry prior to Raman analysis.

Double labeling experiment: Two colonies from each of the individual culture plates were inoculated into M9MM solution consisting of equal amounts of two differently labeled carbon sources at a final concentration of $32 \mathrm{mM}$ in the following combinations a) ${ }^{2} \mathrm{H}$ glucose and ${ }^{13} \mathrm{C}$ fructose b) ${ }^{2} \mathrm{H}$ glucose and ${ }^{13} \mathrm{C}$ galactose c) ${ }^{2} \mathrm{H}$ glucose and ${ }^{13} \mathrm{C}$ naphthalene. These cultures were incubated for three days, with $100 \mu \mathrm{l}$ of the samples drawn out at time points $3,12,24,32,48$ and $72 \mathrm{~h}$ and processed as described for the single labeling experiment prior to Raman analysis.

Raman instrumentation: A Raman microscope (Bio Particle Explorer; rap.ID Particle Systems GmbH, Berlin, Germany) was used for this study. This system suits ideally for bacterial single-cell measurements and is also equipped with an automatic scan mode for automatic measurements of the cells. Single-cell Raman spectra were acquired with an excitation light of $532 \mathrm{~nm}$ generated from a solid-state frequency-doubled Nd:YAG laser (LCM-S-111-NNP25; Laser-export Co.Ltd.). An MPLFLN-BD 100x Olympus objective focused the excitation light onto the sample with a lateral resolution of <1 $\mu \mathrm{m}$ and with approximately $2.5 \mathrm{~mW}$ power at the sample. The exposure time per Raman spectrum was $30 \mathrm{~s}$. The backscattered Raman light at $180^{\circ}$ is diffracted with a single stage monochromator (HE 532; Horiba Jobin Yvon) equipped with a grating of 920 lines $\mathrm{mm}^{-1}$ which offers a resolution of approximately $8 \mathrm{~cm}^{-1}$ and is collected with a thermo electrically cooled CCD camera (DV401-BV; Andor Technology).

Data processing: All the data processing was carried out using Gnu R software with scripts developed by our group..$^{36-37}$

Preprocessing: Calibration of all the Raman spectra was performed by using 4-acetamidophenol (Sigma-Aldrich) as a reference. All Raman spectra were then interpolated to an equidistant wavenumber grid of $1 \mathrm{~cm}^{-1}$. Afterwards, a 2-degree Savitzky-Golay smoothing with a window width of 15 was carried out. Baseline correction was performed using the asymmetric least squares (ALS) method with parameters of $\lambda=3.5, \mathrm{p}=0.001$. Finally, all Raman spectra were vector normalized.

Peak area calculation: For the relative estimation of ${ }^{13} \mathrm{C}$ isotope uptake, integration of peak area ranging between the specified region $\mathbf{A}\left({ }^{13} \mathbf{C}\right)\left(1517-1645 \mathrm{~cm}^{-1}\right)$ was used, a peak area ratio of region corresponding to ${ }^{13} \mathrm{C}$ to the sum of $\mathbf{A}\left({ }^{12} \mathbf{C}\right)\left(1641-1710 \mathrm{~cm}^{-1}\right)$ and ${ }^{13} \mathrm{C}$ was finally calculated. Furthermore, to demonstrate the statistical significance of the isotope uptake, we employed a Wilcoxon test with a p-value less than 0.05 . The altemative hypothesis was that the Raman peak area ratio of the experimental (provided with labeled carbon sources) group was higher than that of the control group (unlabeled glucose $\left({ }^{12} \mathrm{C}\right)$ ). And also, for the relative estimation of ${ }^{2} \mathrm{H}$ is otope uptake in the double labeling experiments, integration of peak area between the regions $\mathbf{A}\left({ }^{2} \mathbf{H}\right)(1995-$ $2347 \mathrm{~cm}^{-1}$ ) was used.

Raman spectra correlation, classification and 2D correlation analysis :

The correlation between the mean Raman spectra was calculated according to Eq. $\rho=\frac{\operatorname{cov}(x, y)}{\sigma_{x} \sigma_{y}}$ where x,y referred to the mean Raman spectra obtained from bacteria cultured in the presence of different carbon sources, $\operatorname{cov}(\mathrm{x}, \mathrm{y})$ means the co-variation of $\mathrm{x}$ and $\mathrm{y}$, while $\rho$ represents the variation of a vector. Classification was achieved by the Tikhonov regularization based partial lease squares regression (TR based PLSR) in order to avoid the influence of between -batch reproducibility. ${ }^{38-39}$ The 2D Raman correlation analysis of the time dependent spectra in the double labeling experiments were achieved using an in house R script based on the Fourier transform approach. ${ }^{40}$ 


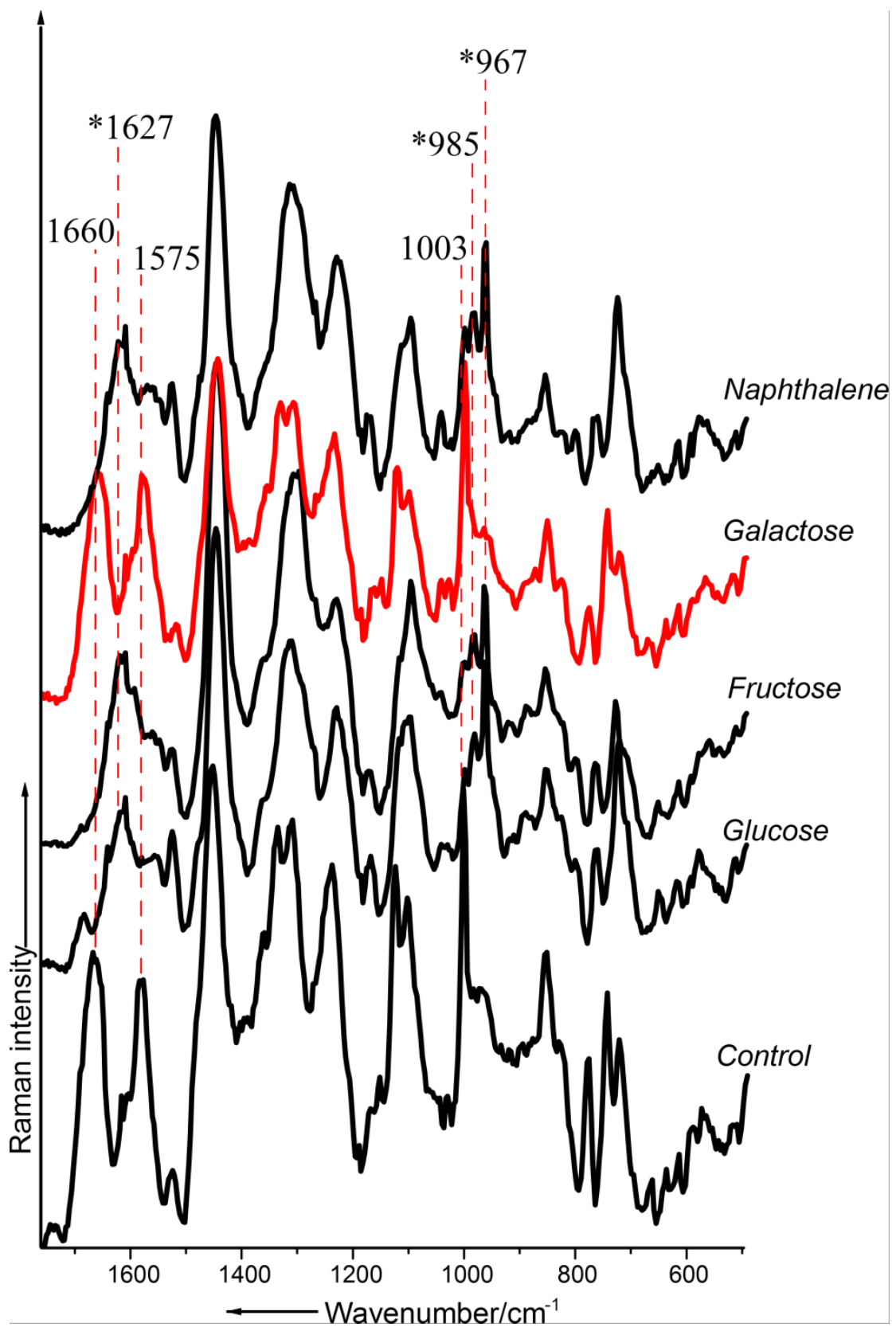

Figure S1: Monitoring metabolic flux of proteins via ${ }^{13} \mathrm{C}$ single labeling approach; Mean spectra of $N$. aromaticivorans cultured under different ${ }^{13} \mathrm{C}$ labeled carbon sources with highlighted regions representing the Roman bands influenced by ${ }^{13} \mathrm{C}$ isotope uptake, the spectrum corresponding to galactose is marked in red to indicate no uptake of isotope. $\left(^{*}\right)$ indicates ${ }^{13} \mathrm{C}$ incorporation

4 


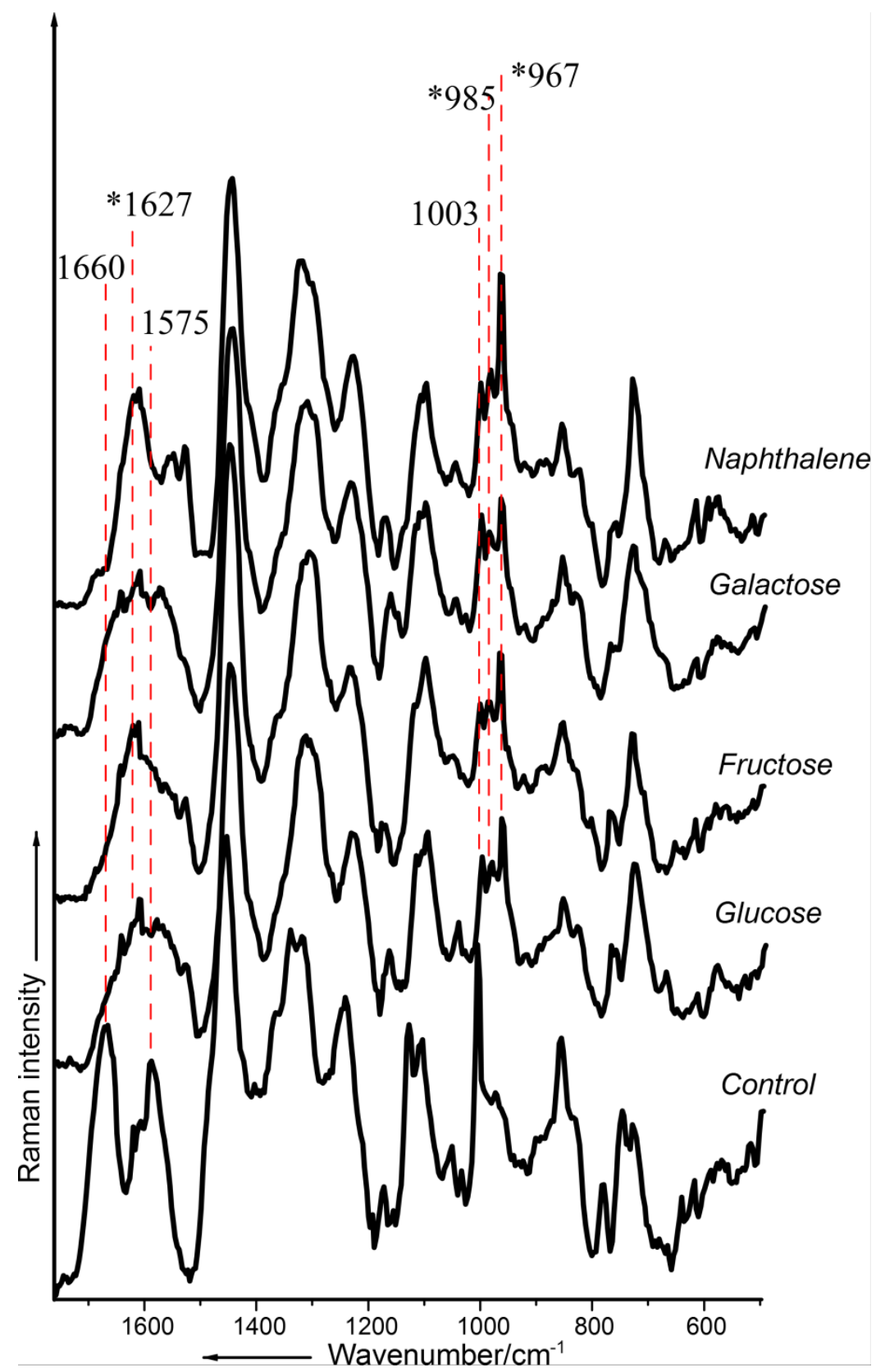

Figure S2: Monitoring metabolic flux of proteins via ${ }^{13} \mathrm{C}$ single labeling approach; Mean spectra of $C$. basilensis cultured under different ${ }^{13} \mathrm{C}$ labeled carbon sources with highlighted regions representing the Raman bands influenced by ${ }^{13} \mathrm{C}$ isotope uptake. (*) indicates ${ }^{13} \mathrm{C}$ incorporation 


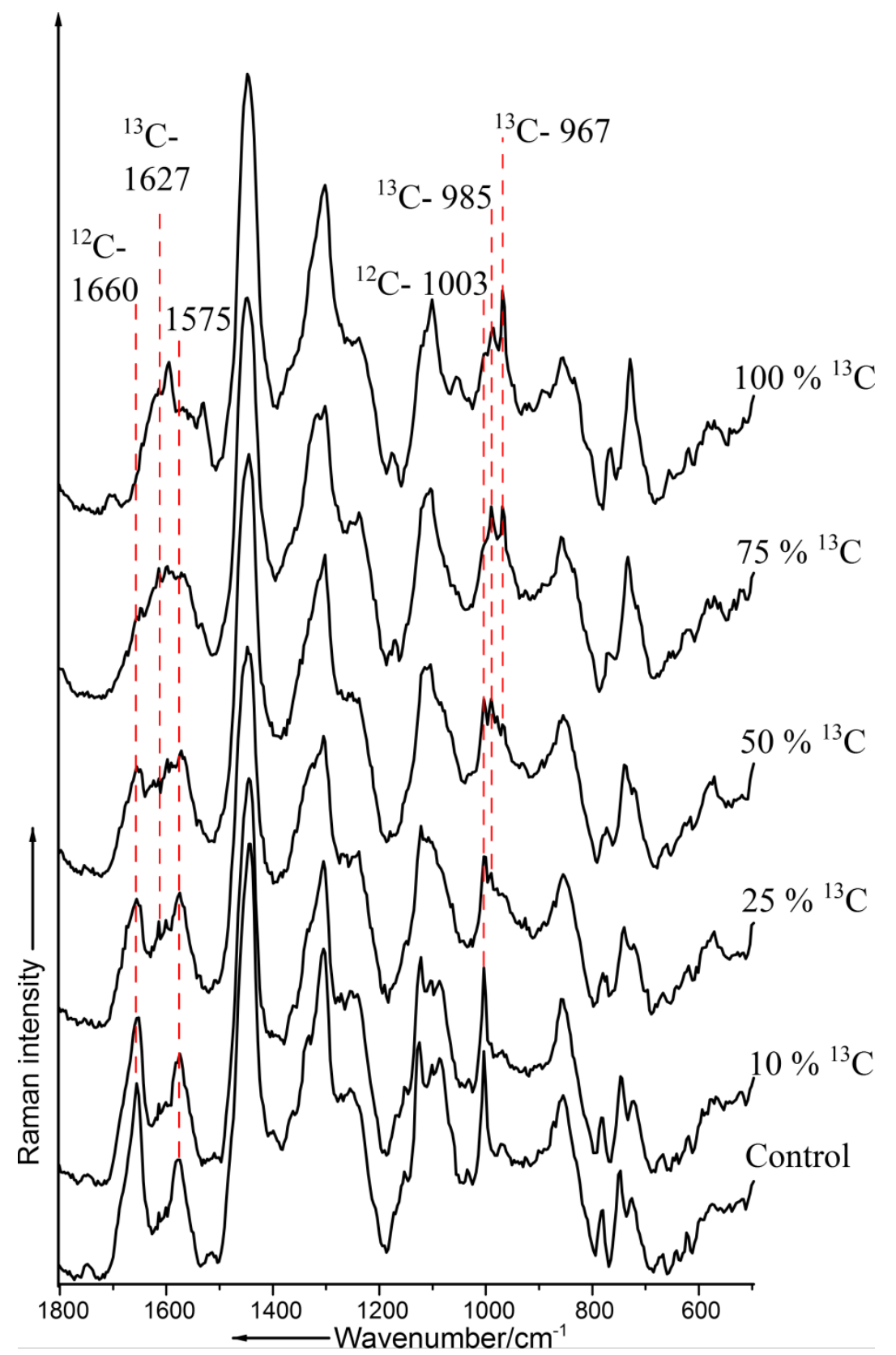

Figure S3: Monitoring metabolic flux of proteins via ${ }^{13} \mathrm{C}$ single labeling approach; Mean spectra of $R$. opacus cultured under increasing percentage of ${ }^{13} \mathrm{C}$ glucose, highlighted regions represent the progression of Raman bands influenced by the percentage of ${ }^{13} \mathrm{C}$ is otope uptake. 

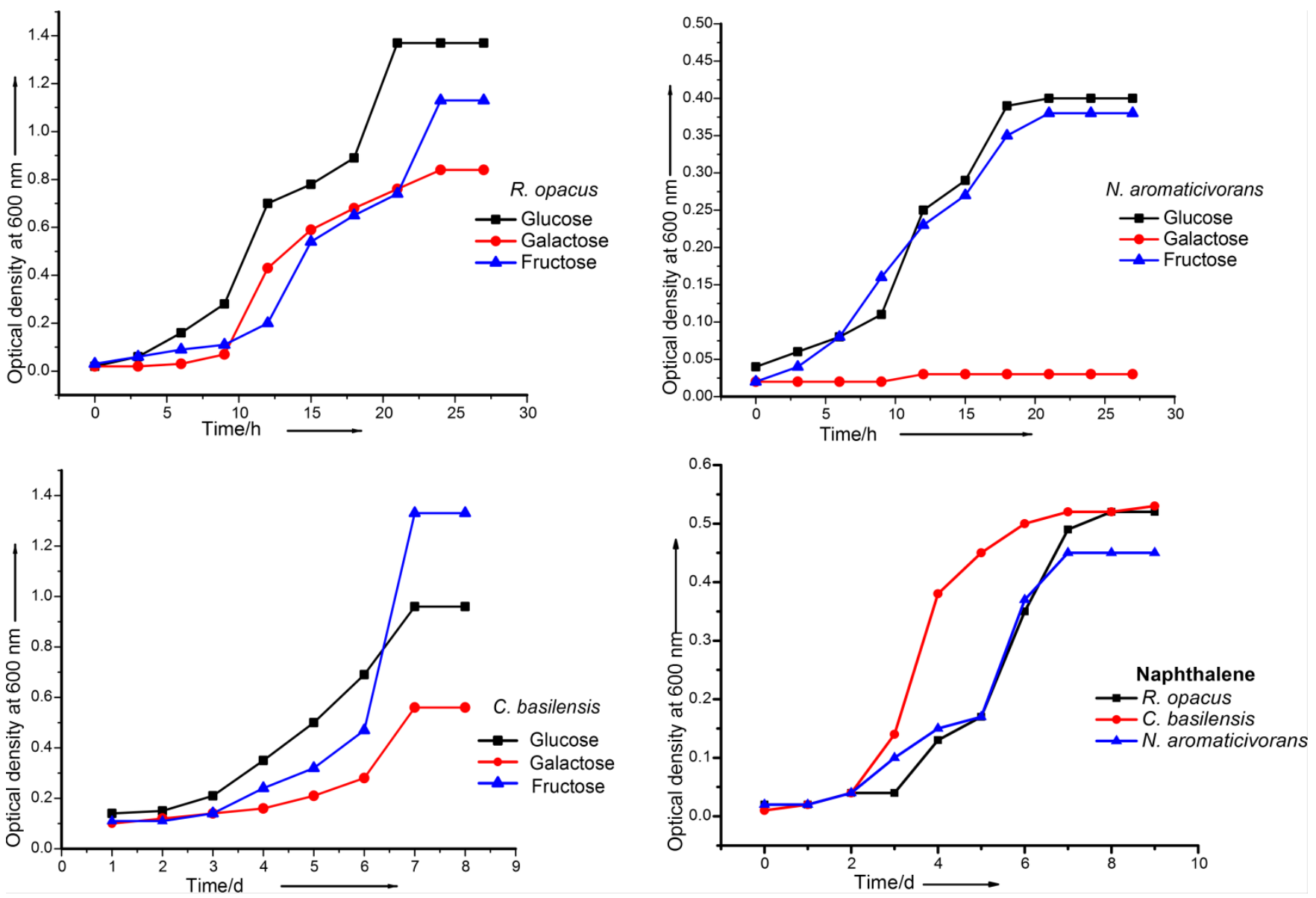

Figure S4: Monitoring metabolic flu x of proteins via ${ }^{13} \mathrm{C}$ single labeling approach; Growth curves of the three naphthalene degrading soil bacteria $R$. opacus, $N$. aromaticivorans and $C$. basilensis cultured in the presence of glucose, galactose and fructose as sole carbon sources and growth curves of these bacteria cultured in the presence of naphthalene as the sole carbon source 
a)
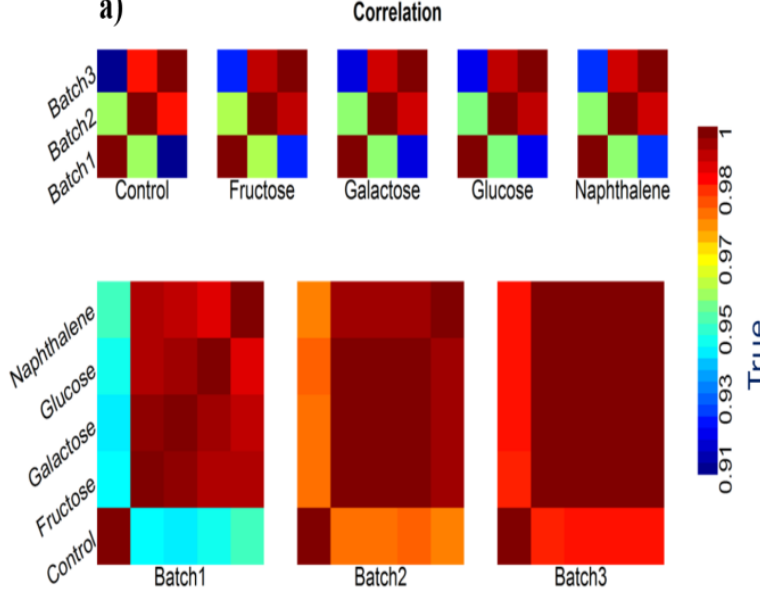

b)

Prediction

\begin{tabular}{lcccccc}
\hline & Control & Fructose & Galactose & Glucose & Naphthalene & Sensitivity $(\%)$ \\
\hline Control & 75 & 0 & 0 & 0 & 0 & 1.00 \\
Fructose & 0 & 34 & 17 & 17 & 7 & 0.45 \\
Galactose & 1 & 20 & 29 & 10 & 16 & 0.38 \\
Glucose & 0 & 11 & 17 & 32 & 5 & 0.43 \\
Naphthalene & 0 & 10 & 0 & 6 & 59 & 0.79 \\
Specificity(\%) & 0.997 & 0.86 & 0.88 & 0.89 & 0.87 & \\
\hline
\end{tabular}

Figure S5: Monitoring metabolic flux of proteins via ${ }^{13} \mathrm{C}$ single labeling approach; a) Spectral correlation of Raman spectra of the species $R$. opacus generated using spectra acquired across three batches of independent experiments. The top was obtained from mean spectra each belonging to one of the three batches, where the low correlations demonstrated a poor reproducibility of the experiment. While the bottom result from mean spectra when the bacterium was cultured under different carbon sources. It is seen here that $R$. opacus features similar metabolism properties for the four investigated carbon sources. The low correlation between the control group (cultured with glucose without isotope labeling) and the other four experimental groups demonstrated the uptake of the four carbon sources. b) Confusion matrix representing the classification results to distinguish Raman spectra measured under different carbon sources. The low sensitivities indicated the poor separation among spectra obtained when different carbon sources were provided. Thus this also reflects a similar metabolism of carbon sources. The classification was achieved by Tikhonov regularization method based partial least squares regression to depress the influence of the low between batch reproducibility.

a)
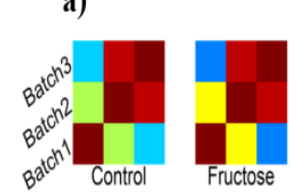
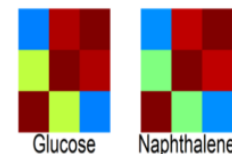

Correlation
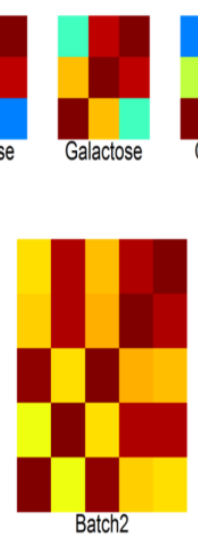

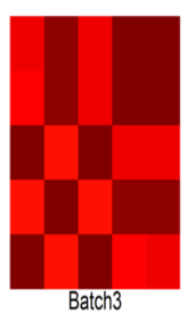

b)

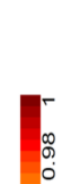

Prediction

\begin{tabular}{lcccccc}
\hline & Control & Fructose & Galactose & Glucose & Naphthalene & Sensitivity $\%$ \\
\hline Control & 54 & 1 & 21 & 0 & 0 & 0.71 \\
Fructose & 0 & 76 & 0 & 0 & 0 & 1.00 \\
Galactose & 12 & 0 & 63 & 0 & 0 & 0.84 \\
\hline Glucose & 0 & 2 & 0 & 64 & 9 & 0.85 \\
Naphthalene & 0 & 3 & 0 & 21 & 51 & 0.68 \\
Specificity (\%) & 0.96 & 0.98 & 0.94 & 0.93 & 0.97 & \\
\hline
\end{tabular}

Figure S6: Monitoring metabolic flux of proteins via ${ }^{13} \mathrm{C}$ single labeling approach; a) Spectral correlation of Raman spectra of the species $N$. aromaticivorans generated using spectra acquired across three batches of independent experiments. The top was obtained from mean spectra each belonging to one of the three batches, where the low correlations demonstrated a poor reproducibility of the experiment. While the bottom result from mean spectra when the bacterium was cultured under different carbon sources. A high correlation was observed between control group (cultured with glucose without isotope labeling) and the experimental group with galactose as carbon source, indicating no uptake of galactose. The low correlation between the control group and the other three experimental groups demonstrated the uptake of the three carbon sources. It is obvious that $N$. aromaticivorans features similar metabolism properties for these three investigated carbon sources. b) Confusion matrix representing the classification results to distinguish Raman spectra measured under different carbon sources. The major similarity in the Raman spectra of the control group and the experimental group galactose and also between glucose and naphthalene group results in reduced sensitivity in separation of these groups. The classification was achieved by Tikhonov regularization method based partial least squares regression to depress the influence of the low between batch reproducibility. 
a)
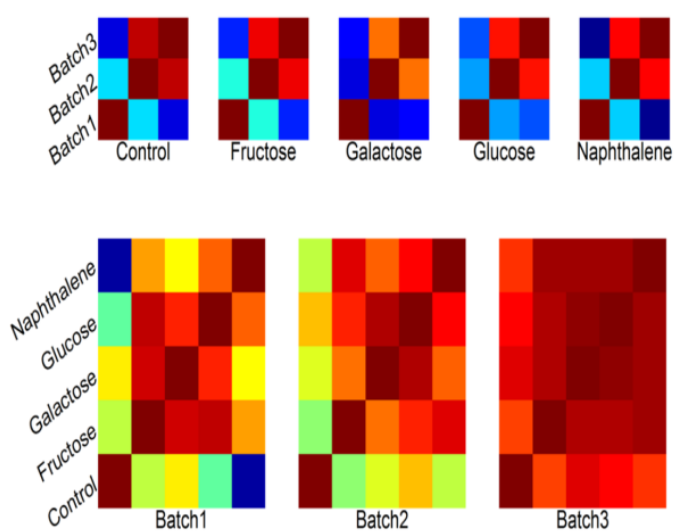

Figure S7: Monitoring metabolic flux of proteins via ${ }^{13} \mathrm{C}$ species $C$. basilensis generated using spectra acquired across three batches of independent experiments. The top was obtained from mean spectra each belonging to one of the three batches, where the low correlations demonstrated a poor reproducibility of the experiment. While the bottom; when the bacterium was cultured under different carbon sources. It is seen here that $C$. basilensis features approximately similar metabolism properties for all the investigated carbon sources. And, the low correlation between the control group (cultured with glucose without isotope labeling) and the other four experimental groups demonstrated the uptake of all the four carbon sources. b) Confusion matrix representing the classification results to distinguish Raman spectra measured under different carbon sources. The low sensitivities indicated the poor separation among spectra obtained when different carbon sources were provided. The classification was achieved by Tikhonov regularization method based partial least squares regression to depress the influence of the low between batch reproducibility. 


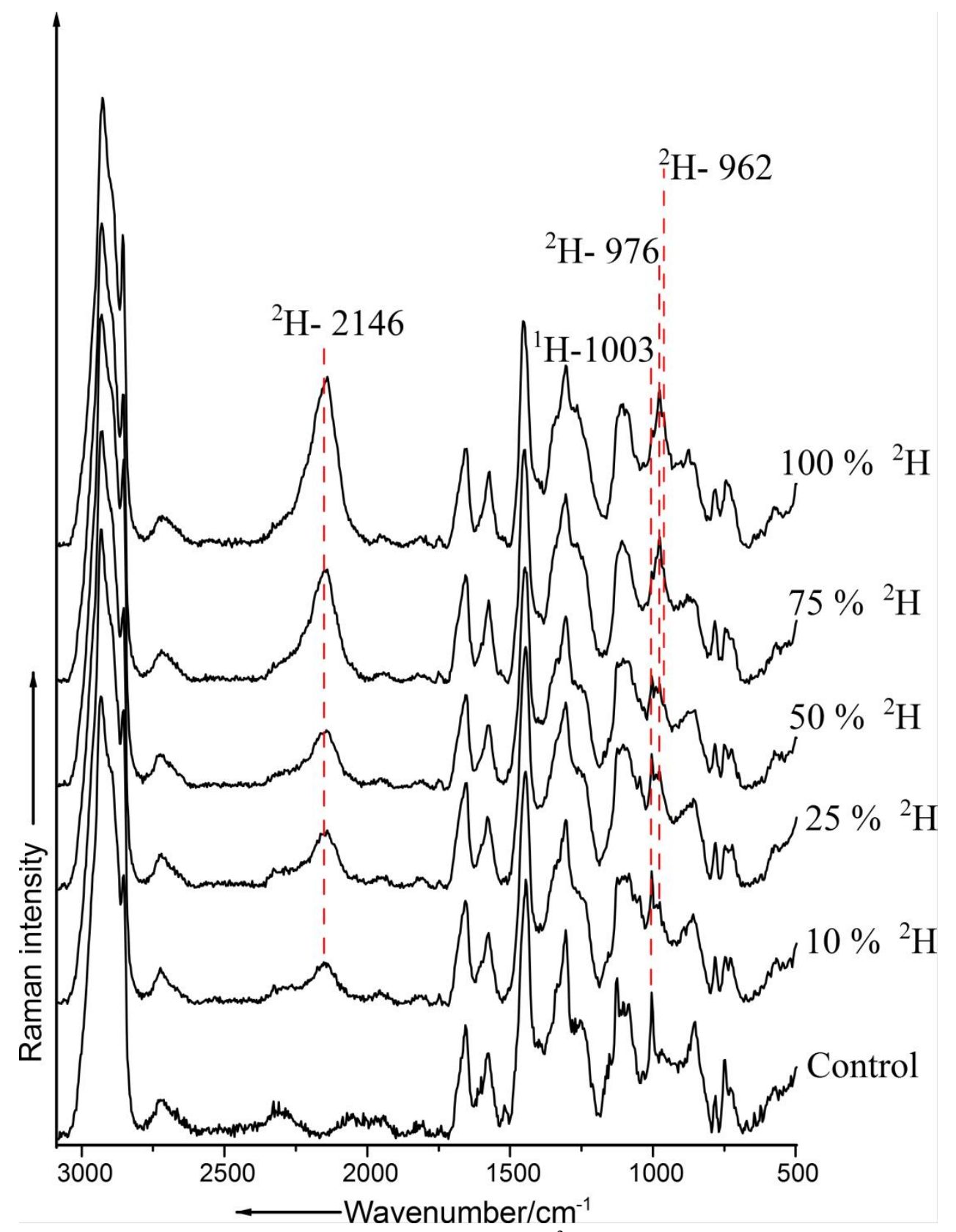

Figure S8: Monitoring metabolic flux of proteins via ${ }^{2} \mathrm{H}$ single labeling approach; Mean spectra of $R$. opacus cultured under increasing percentage of ${ }^{2} \mathrm{H}$ glucose, highlighted regions represent the progression of Raman bands influenced by the percentage of ${ }^{2} \mathrm{H}$ is otope uptake. 


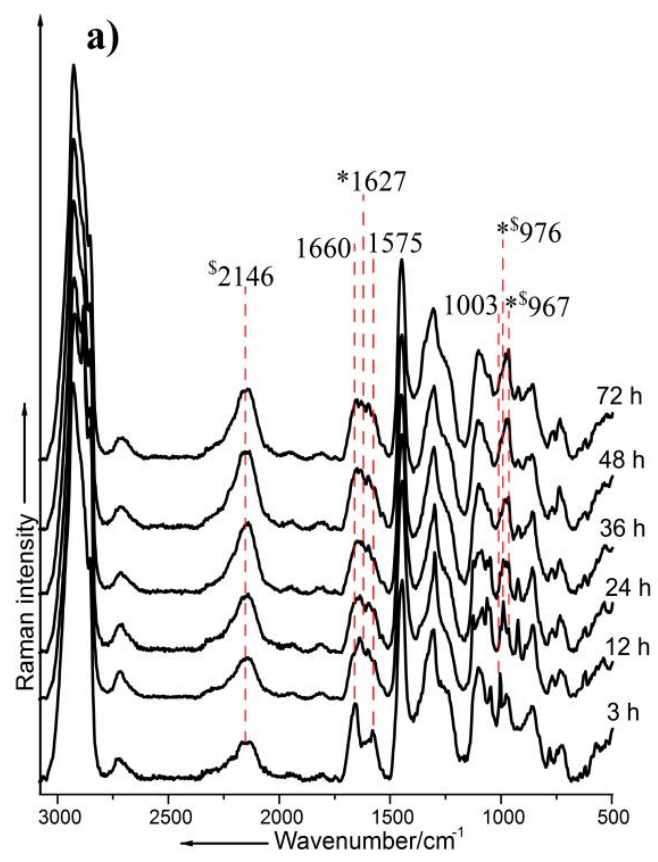

b)
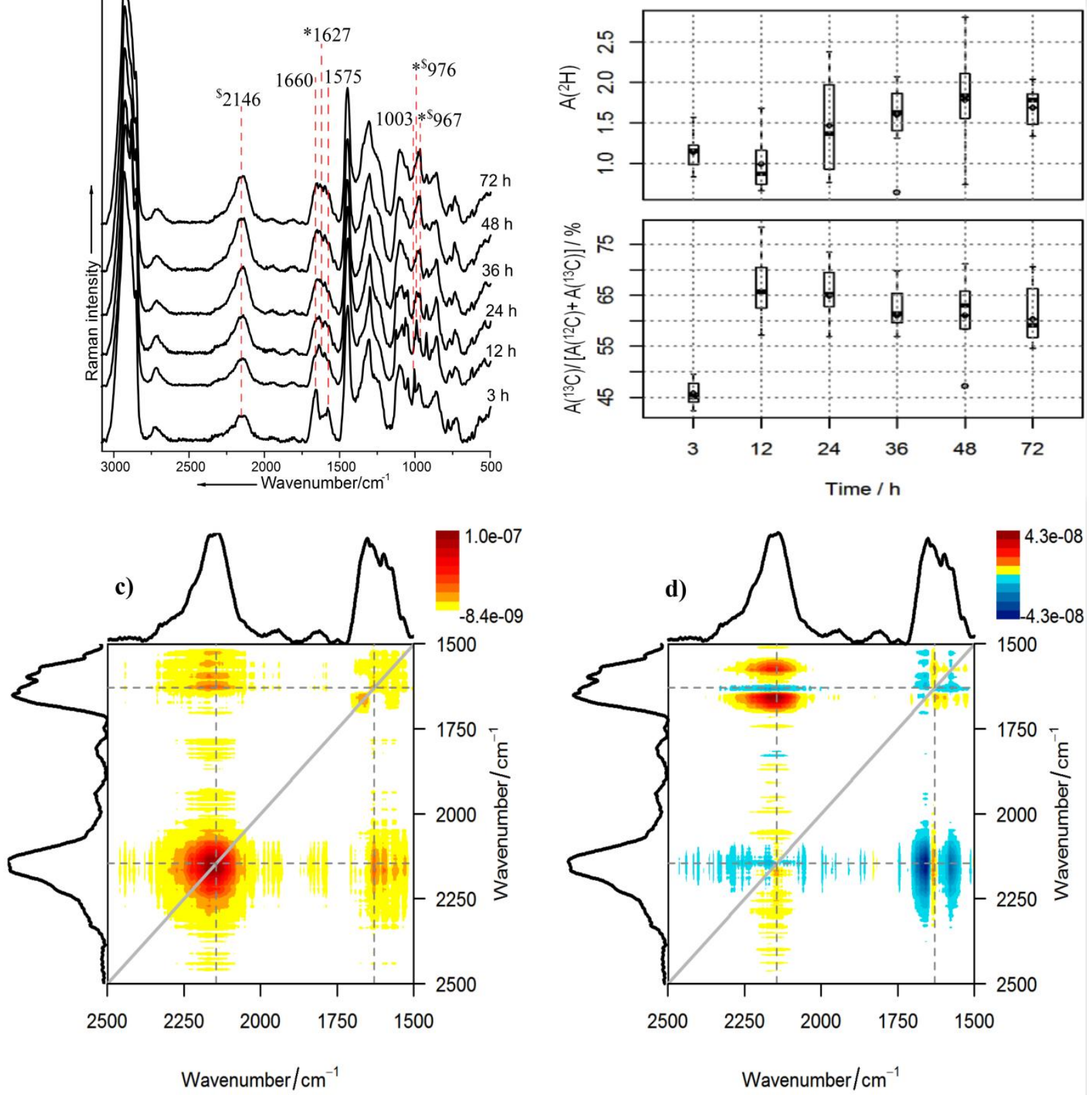

Figure S9. Visualization of carbon catabolite repression via ${ }^{2} \mathrm{H}$ and ${ }^{13} \mathrm{C}$ double labeling approach a) Time dependent spectra of R. opacus cultured with a combination of ${ }^{2} \mathrm{H}$ glucose and ${ }^{13} \mathrm{C}$ fructose as carbon sources, $(\$)$ indicates ${ }^{2} \mathrm{H}$ incomoration, $(*)$ indicates ${ }^{13} \mathrm{C}$ incorporation, (*\$) indicates incorporation of both ${ }^{2} \mathrm{H}$ and ${ }^{13} \mathrm{C}$ isotope (b) Observation of the level of ${ }^{2} \mathrm{H}$ and ${ }^{13} \mathrm{C}$ is otope incomoration with the standard box plot showing population quartiles based on peak area calculations $\mathrm{A}\left({ }^{13} \mathrm{C}\right) /\left[\mathrm{A}\left({ }^{12} \mathrm{C}\right)+\mathrm{A}\left({ }^{13} \mathrm{C}\right)\right]$ \& $\left.\mathrm{A}\left({ }^{2} \mathrm{H}\right) \mathrm{c}\right)$ Synchronous 2D Raman correlation spectrum showing autopeaks at $1575,1627,1660$ and $\left.2146 \mathrm{~cm}^{-1} \mathrm{~d}\right)$ Asynchronous 2D Raman correlation spectrum of $R$. opacus $\left({ }^{2} \mathrm{H}\right.$ glucose $+{ }^{13} \mathrm{C}$ fructose) from 3 to $72 \mathrm{~h}$ in the spectral region from 1500 to $2500 \mathrm{~cm}^{-1}$ as obtained from the time dependent Raman spectra. Positive cross peaks around the position $(1627,2146) \mathrm{cm}^{-1}$ and negative cross peaks around the position $(1575,2146) \mathrm{cm}^{-1},(1660,2146) \mathrm{cm}^{-1}$ can be identified in this spectrum. This pattem indicates a characteristic peak shift of the band at $1660 \mathrm{~cm}^{-1}$. Red indicates positive and blue indicates negative sign of the peaks respectively. Time dependent and 2D Raman correlation spectra show cometabolism or co-utilization of both glucose and fructose by this bacterium 
a)
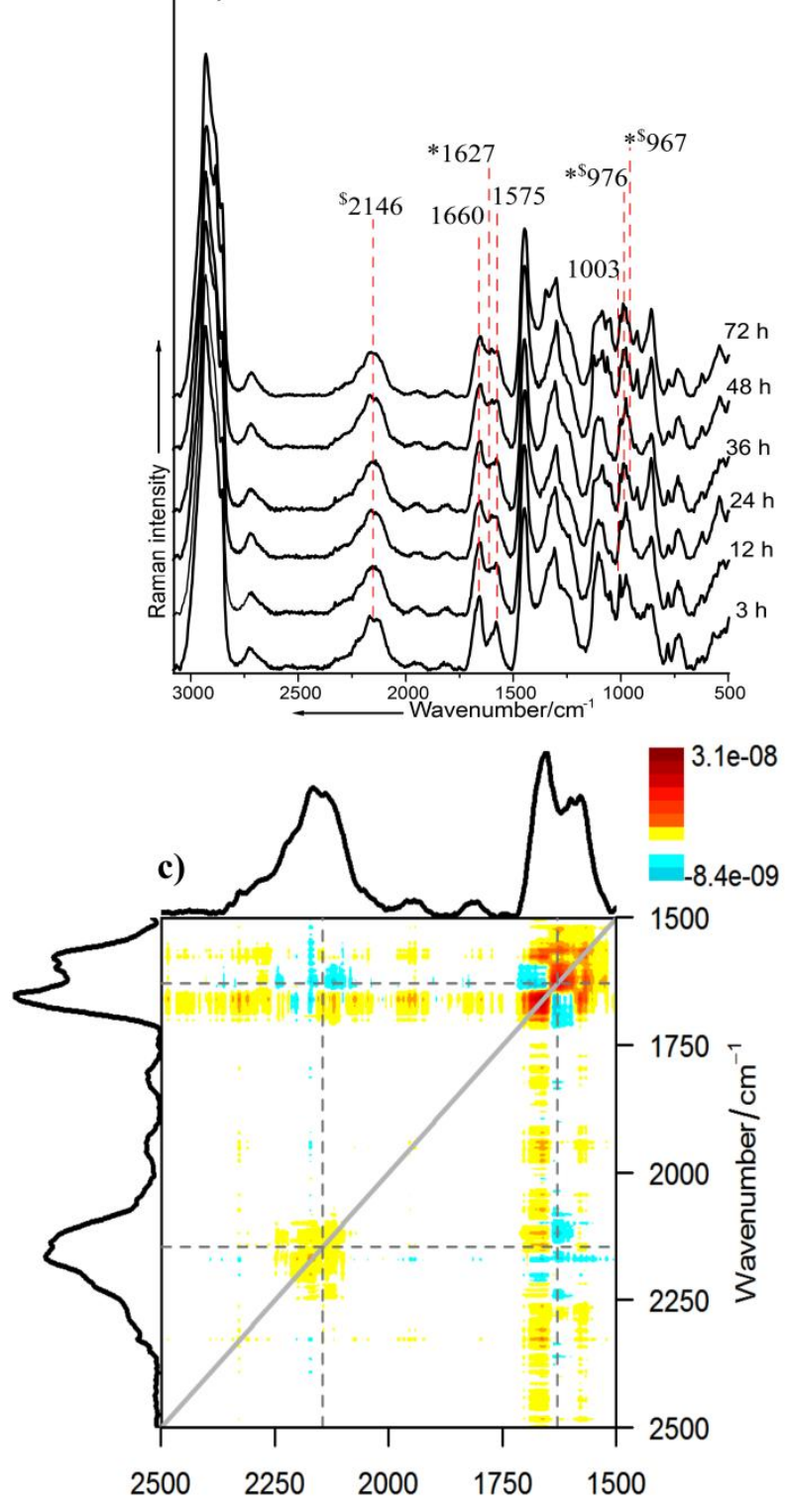

Wavenumber $/ \mathrm{cm}^{-1}$ b)
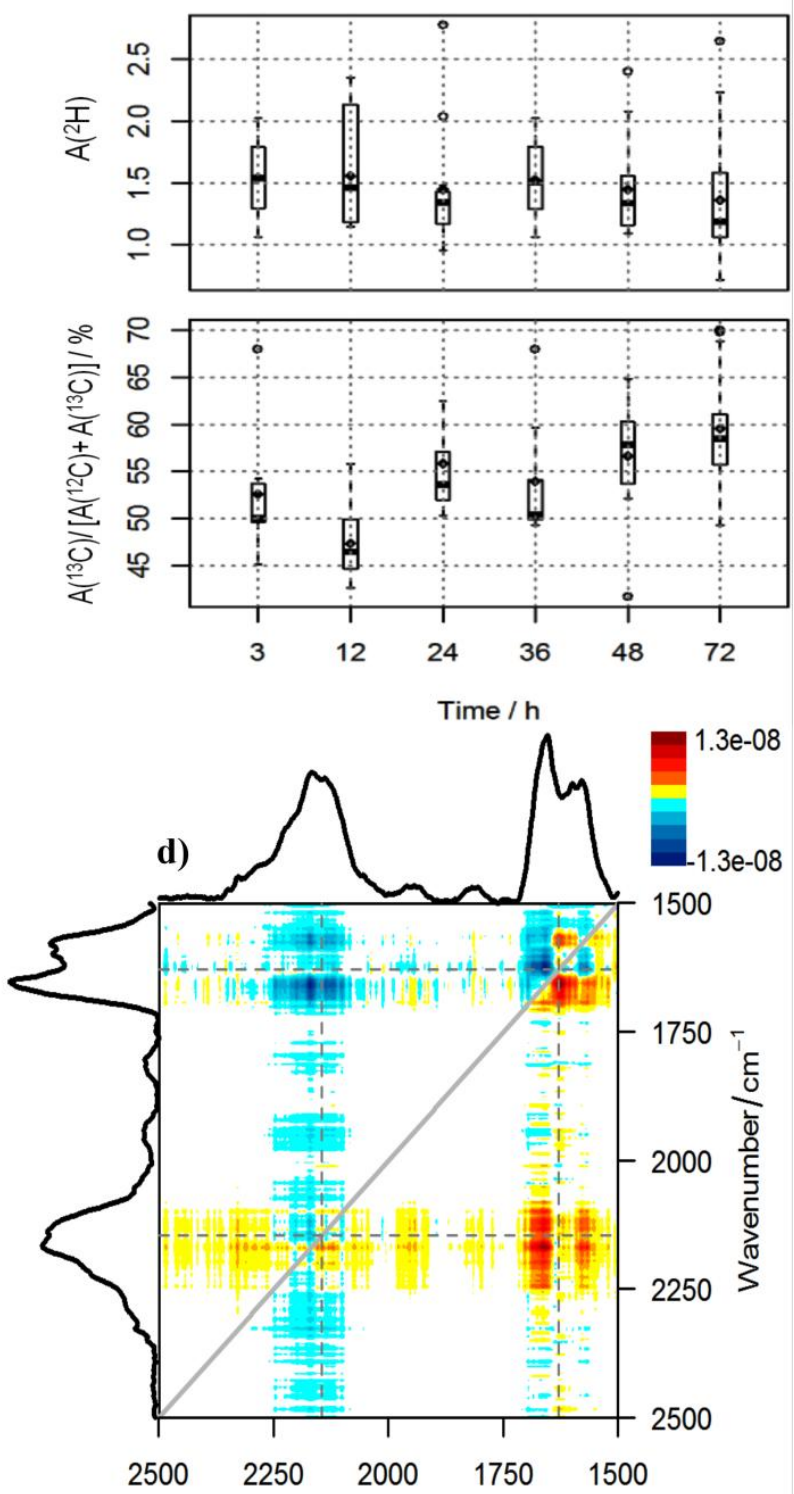

Wavenumber $/ \mathrm{cm}^{-1}$

Figure S10. Visualization of carbon catabolite repression via ${ }^{2} \mathrm{H}$ and ${ }^{13} \mathrm{C}$ double labeling approach a) Time dependent spectra of $R$. opacus cultured with a combination of ${ }^{2} \mathrm{H}$ glucose and ${ }^{13} \mathrm{C}$ naphthalene as carbon sources, $(\$)$ indicates ${ }^{2} \mathrm{H}$ incorporation, $\left({ }^{*}\right)$ indicates ${ }^{13} \mathrm{C}$ incoporation, (*\$) indicates incorporation of both ${ }^{2} \mathrm{H}$ and ${ }^{13} \mathrm{C}$ is otope; At $3 \mathrm{~h}$, the spectral pattem indicates predominant appearance of bands related to ${ }^{2} \mathrm{H}$ incorporation and shows little variation with time. The changes due to the ${ }^{13} \mathrm{C}$ incorporation from naphthalene were only visible starting from $12 \mathrm{~h}$ where in the band shape is changing progressively with time and at $72 \mathrm{~h}$ the amide I band at $1660 \mathrm{~cm}^{-1}$ was completely shifted to $1627 \mathrm{~cm}^{-1}$. b) Observation of the level of ${ }^{2} \mathrm{H}$ and ${ }^{13} \mathrm{C}$ isotope incorporation with the standard box plot showing population quartiles based on peak area calculations $\mathrm{A}\left({ }^{13} \mathrm{C}\right) /\left[\mathrm{A}\left({ }^{12} \mathrm{C}\right)+\mathrm{A}\left({ }^{13} \mathrm{C}\right)\right] \& \mathrm{~A}\left({ }^{2} \mathrm{H}\right)$; this plot indicates that there is uptake of both the isotopes with time; however the increase in the incorporation of both the is otopes is not very high during the course of $72 \mathrm{~h}$. The ${ }^{2} \mathrm{H}$ incorporation is stable post an initial flow of incorporation till $12 \mathrm{~h}$; this is also the time point wherein the naphthalene begins to be metabolized. This pattem indicates a slowing down of metabolis $m$ once a complex carbon source like naphthalene begins to be metabolized along with glucose. c) Synchronous 2D Raman correlation spectrum; consists of four autopeaks at 1575, 1627, 1660 and $2146 \mathrm{~cm}^{-1}$. The former three autopeaks are strong and the latter autopeak is weak in intensity due to minor changes at this position with time. The two autopeaks at 1627 and $1660 \mathrm{~cm}^{-1}$ are negatively correlated indicated by the presence of negative cross peaks; here it means that the band at 1660 is decreasing coupled with the slow increase in the band at $1627 \mathrm{~cm}^{-1}$. This pattern suggests a very slow uptake of ${ }^{13} \mathrm{C}$ isotope resulting from the utilization of naphthalene. This can also be observed in the time dependent spectra indicating shift of the amide I band at 1660 to $1627 \mathrm{~cm}^{-1}$ and subsequent supe- 
rimposition over the nucleic acid band at $1575 \mathrm{~cm}^{-1}$. d) Asynchronous 2D Raman correlation spectrum of $R$. opacus $\left({ }^{2} \mathrm{H}\right.$ glucose + ${ }^{13} \mathrm{C}$ naphthalene) from 3 to $72 \mathrm{~h}$ in the spectral region from 1500 to $2500 \mathrm{~cm}^{-1}$ as obtained from the time dependent Raman spectra; asynchronous spectrum shows positive cross peaks around coordinates $(1575,2146) \mathrm{cm}^{-1},(1627,2146) \mathrm{cm}^{-1}$ and $(1660,2146)$ $\mathrm{cm}^{-1}$. As explained previously, such a pattern is indicative of a prominent peak shift, in this case resulting from the uptake of ${ }^{13} \mathrm{C}$ is otope from naphthalene. The sign of the asynchronous cross peak around the coordinates $(1660,2146) \mathrm{cm}^{-1}$ is positive but the corresponding synchronous cross peak at the same position is negative. This indicates that the spectral intensity change at $1660 \mathrm{~cm}^{-1}$ induced by ${ }^{13} \mathrm{C}$ incorporation from naphthalene lags that at $2146 \mathrm{c} \mathrm{m}^{-1}$ induced by ${ }^{2} \mathrm{H}$ incorporation from glucose. These results suggest that glucose is metabolized at a faster rate when compared to naphthalene which is a complex carbon source; however the utilization of naphthalene is not entirely repressed in the presence of glucose. As results from the time dependent and the 2D Raman correlation spectra clearly show that there are changes induced by utilization of naphthalene starting from $12 \mathrm{~h}$. Thereby, we can deduce here that the presence of glucose does not repress the utilization of naphthalene as an alternate carbon source; however the utilization of naphthalene takes place at a much slower rate when compared to glucose. 
a)
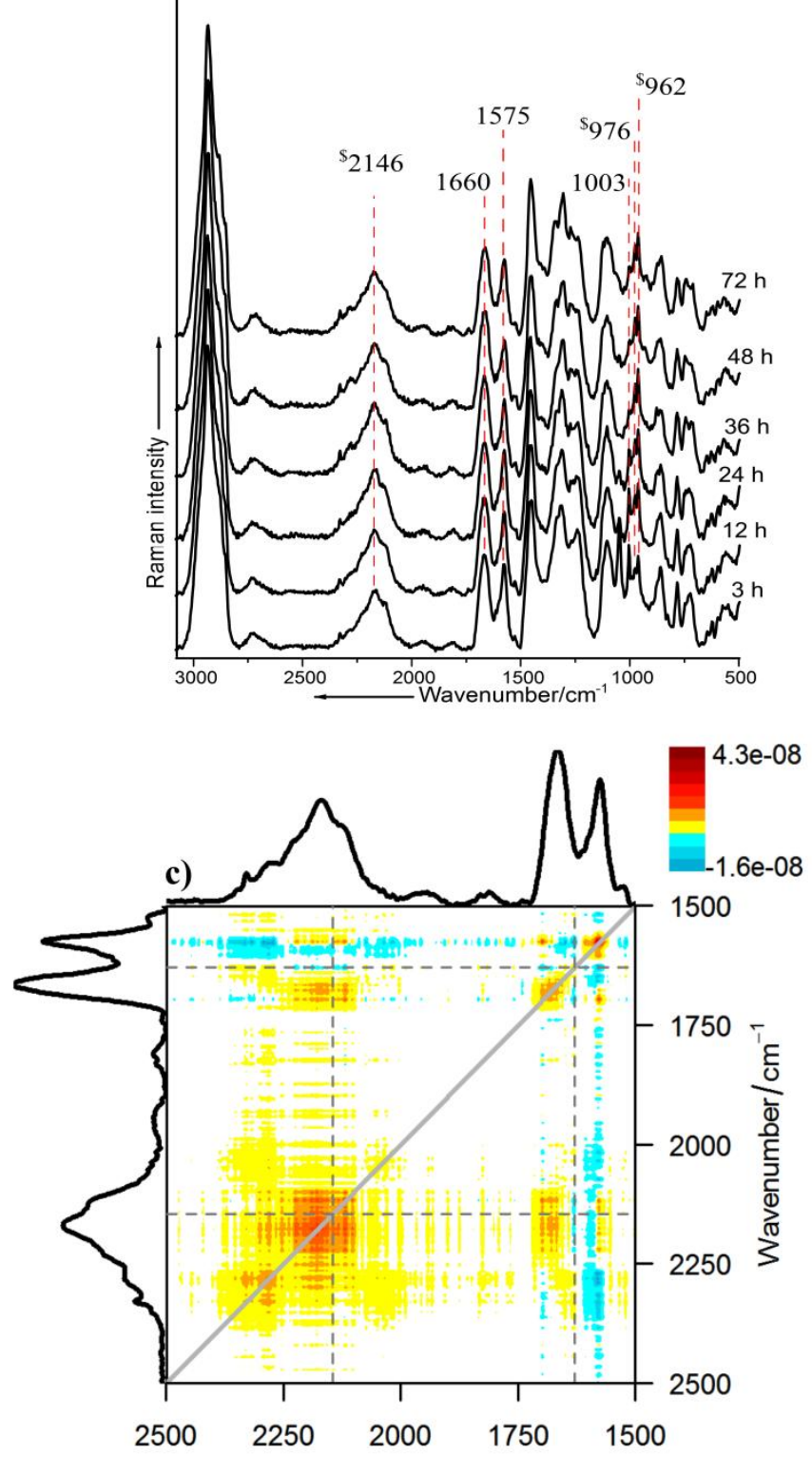

Wavenumber $/ \mathrm{cm}^{-1}$ b)
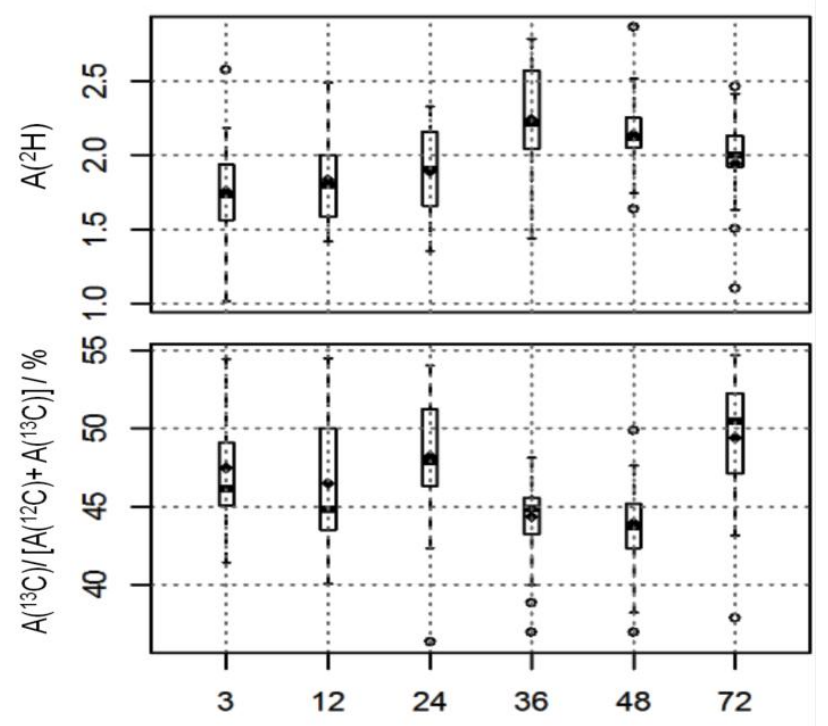

Time / h

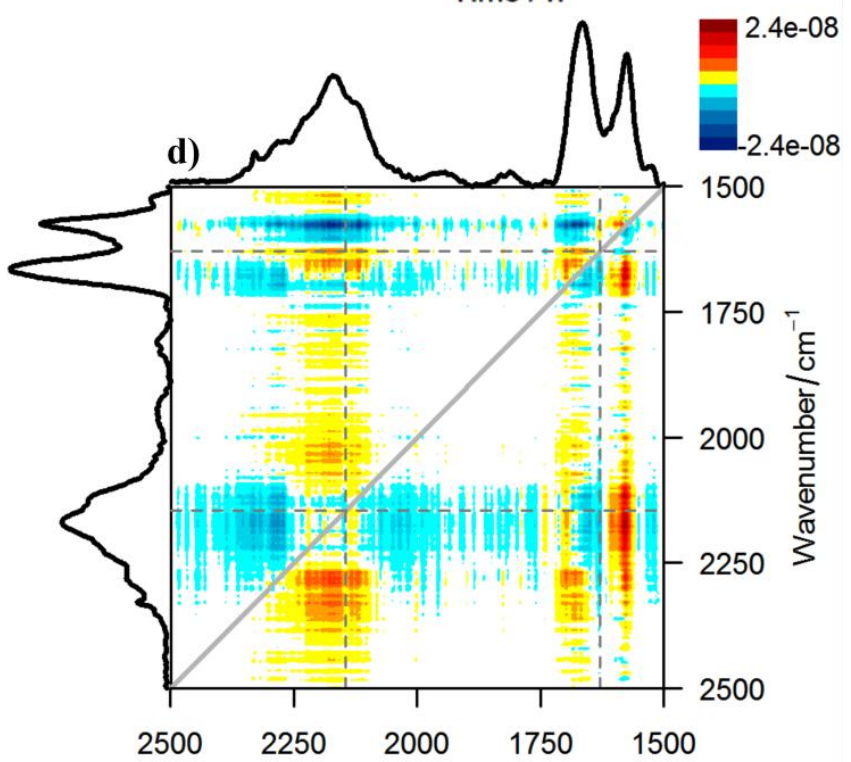

Wavenumber $/ \mathrm{cm}^{-1}$

Figure S11. Visualization of carbon catabolite repression via ${ }^{2} \mathrm{H}$ and ${ }^{13} \mathrm{C}$ double labeling approach a) Time dependent spectra of $N$. aromaticivorans cultured with a combination of ${ }^{2} \mathrm{H}$ glucose and ${ }^{13} \mathrm{C}$ galactose as carbon sources, (\$) indicates ${ }^{2} \mathrm{H}$ incorporation; at $3 \mathrm{~h}$ the predominant changes in the spectrum are due to the incorporation of ${ }^{2} \mathrm{H}$ isotope resulting from the utilization of glucose. During the course of $72 \mathrm{~h}$, these changes were observed to be increasing in intensity to a minimal extent. However, there were no changes observed indicating the incorporation of ${ }^{13} \mathrm{C}$ is otope due to utilization of galactose during the course of $72 \mathrm{~h}$. b) Observation of the level of ${ }^{2} \mathrm{H}$ and ${ }^{13} \mathrm{C}$ is otope incomoration with the standard box plot showing population quartiles based on peak area calculations $\mathrm{A}\left({ }^{13} \mathrm{C}\right) /\left[\mathrm{A}\left({ }^{12} \mathrm{C}\right)+\mathrm{A}\left({ }^{13} \mathrm{C}\right)\right]$ \& $\mathrm{A}\left({ }^{2} \mathrm{H}\right)$; this plot indicates only a small relative increase in the uptake of ${ }^{2} \mathrm{H}$ is otope with time which may be attributed to slow metabolic activity. And, in comparison the box plot depicting ${ }^{13} \mathrm{C}$ incorporation shows only slight variation due to the changes in the $1660 \mathrm{~cm}^{-1}$ band resulting mostly from heterogeneous biomolecular distribution c) Synchronous 2D Raman correlation spectrum; consists of three autopeaks at 1575, 1660 and $2146 \mathrm{~cm}^{-1}$ indicating a change in these regions. The autopeak at $2146 \mathrm{~cm}^{-1}$ is strong while the former two are weak in intensity. This indicates an obvious change at $2146 \mathrm{~cm}^{-1}$ induced by ${ }^{2} \mathrm{H}$ incorporation from glucose whereas the minor changes in the other two regions can be attributed to relative intensity variation as explained previously d) Asynchronous 2D Raman correlation spectrum of $N$. aromaticivorans $\left({ }^{2} \mathrm{H}\right.$ glucose $+{ }^{13} \mathrm{C}$ galactose $)$ from 3 to $72 \mathrm{~h}$ in the spectral region from 1500 to $2500 \mathrm{~cm}^{-1}$ as obtained from the time dependent Raman spectra; as ynchronous spectrum shows a negative cross peak around coordinates $(1660,2146) \mathrm{cm}^{-1}$. This means that the spectral intensity change at 1660 $\mathrm{cm}^{-1}$ lags that at $2146 \mathrm{~cm}^{-1}$. As previously explained the changes due to heterogeneous molecular distribution are non sequential 
and in this case lags the changes occurring due to ${ }^{2} \mathrm{H}$ isotope uptake from utilization of glucose. Importantly it is seen here that, no major changes were observed in the spectral pattern which indicated an incorporation of ${ }^{13} \mathrm{C}$ is otope due to the utilization of galactose during the course of $72 \mathrm{~h}$. These results clearly suggest that the utilization of galactose as an alternate carbon source is affected by CCR induced in the presence of glucose in this bacterium. Also, the influence of the reduced transport of galactose into the cells may further delay its utilization as observed in the single labeling experiments. 


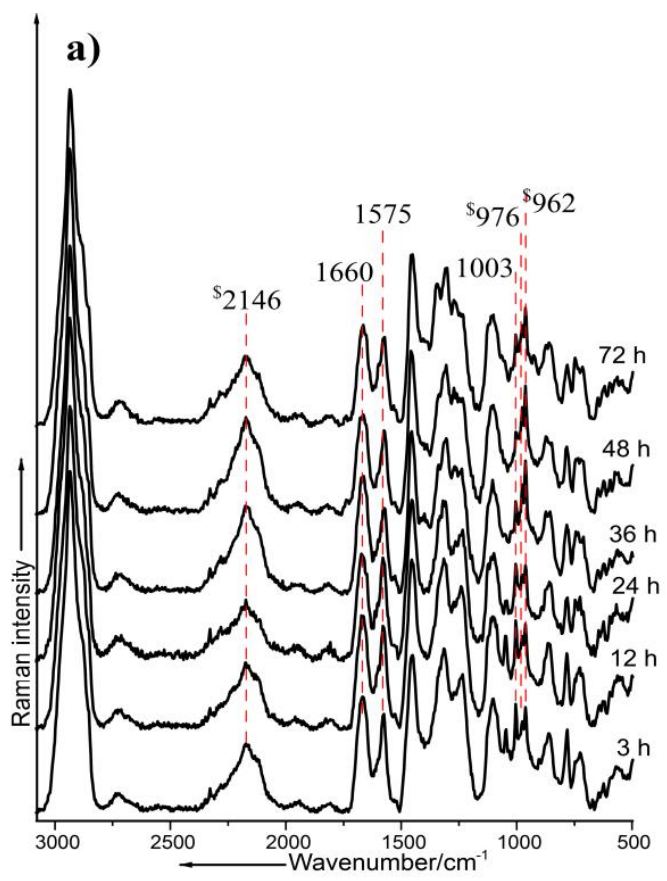

b)
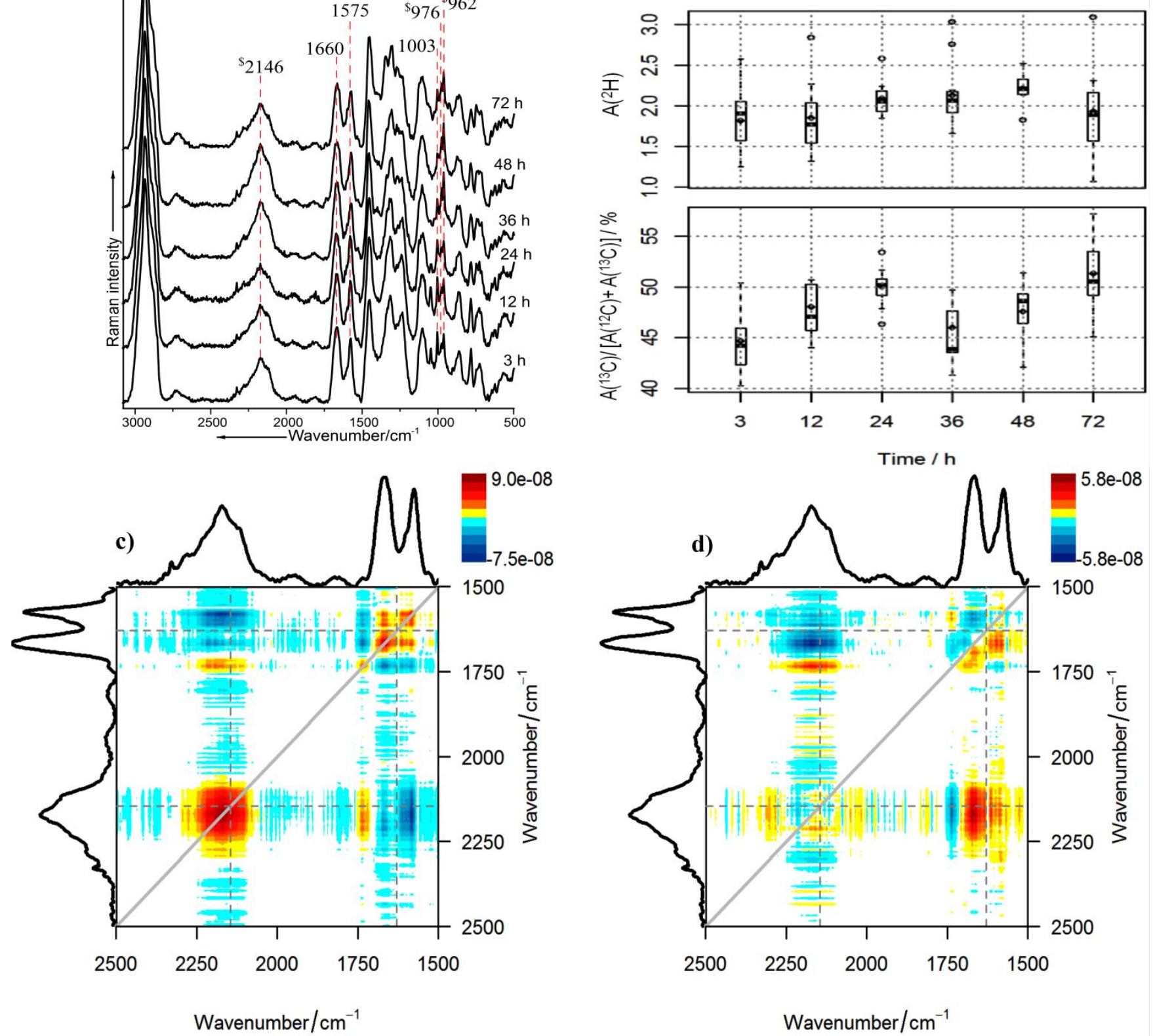

Wavenumber $/ \mathrm{cm}^{-1}$

Wavenumber $/ \mathrm{cm}^{-1}$

Figure S12. Visualization of carbon catabolite repression via ${ }^{2} \mathrm{H}$ and ${ }^{13} \mathrm{C}$ double labeling approach a) Time dependent spectra of $N$. aromaticivorans cultured with a combination of ${ }^{2} \mathrm{H}$ glucose and ${ }^{13} \mathrm{C}$ fructose as carbon sources, $(\$)$ indicates ${ }^{2} \mathrm{H}$ incorporation; At $3 \mathrm{~h}$, the predominant changes in the spectrum are due to the incorporation of ${ }^{2} \mathrm{H}$ is otope resulting from the utilization of glucose. During the course of $72 \mathrm{~h}$, these changes were observed to be increasing in intensity to a minimal extent. However, there were no changes observed indicating the incorporation of ${ }^{13} \mathrm{C}$ isotope due to utilization of fructose during the course of $72 \mathrm{~h}$. b) Observation of the level of ${ }^{2} \mathrm{H}$ and ${ }^{13} \mathrm{C}$ isotope incorporation with the standard box plot showing population quartiles based on peak area calculations $\mathrm{A}\left({ }^{13} \mathrm{C}\right) /\left[\mathrm{A}\left({ }^{12} \mathrm{C}\right)+\mathrm{A}\left({ }^{13} \mathrm{C}\right)\right] \& \mathrm{~A}\left({ }^{2} \mathrm{H}\right)$; this plot indicates a small relative increase in the uptake of ${ }^{2} \mathrm{H}$ is otope with time which may be attributed to slow metabolic activity, and in comparis on the box plot depicting ${ }^{13} \mathrm{C}$ incorporation shows only slight variation due to the changes in the $1660 \mathrm{~cm}^{-1}$ band resulting mostly from heterogeneous biomolecular distribution. c) Synchronous 2D Raman correlation spectrum; consists of three autopeaks at 1575, 1660 and $2146 \mathrm{~cm}^{-1}$ indicating a change in these regions. The autopeak at $2146 \mathrm{~cm}^{-1}$ is strong while the former two are weak in intensity. This indicates a major change at $2146 \mathrm{~cm}^{-1}$ induced by ${ }^{2} \mathrm{H}$ incorporation from glucose whereas the minor changes in the other two regions can be attributed to relative intensity variation as explained previously. d) Asynchronous 2D Raman correlation spectrum of $N$. aromaticivorans $\left({ }^{2} \mathrm{H}\right.$ glucose $+{ }^{13} \mathrm{C}$ fructose) from 3 to $72 \mathrm{~h}$ in the spectral region from 1500 to $2500 \mathrm{~cm}^{-1}$ as obtained from the time dependent Raman spectra; asynchronous spectrum 
shows a positive cross peak around coordinates $(1660,2146) \mathrm{cm}^{-1}$. This means that the spectral intensity change at $1660 \mathrm{~cm}^{-1}$ precedes that at $2146 \mathrm{~cm}^{-1}$. As previously explained the changes due to heterogeneous molecular distribution are non sequential and in this case precedes the changes occurring due to ${ }^{2} \mathrm{H}$ isotope uptake from utilization of glucose. Importantly it is seen here that, no major changes were observed in the spectral pattem which indicated an incorporation of ${ }^{13} \mathrm{C}$ isotope due to the utilization of fructose during the course of $72 \mathrm{~h}$. These results clearly suggest that the utilization of fructose as an altemate carbon source is affected by CCR induced in the presence of glucose in this bacterium. 

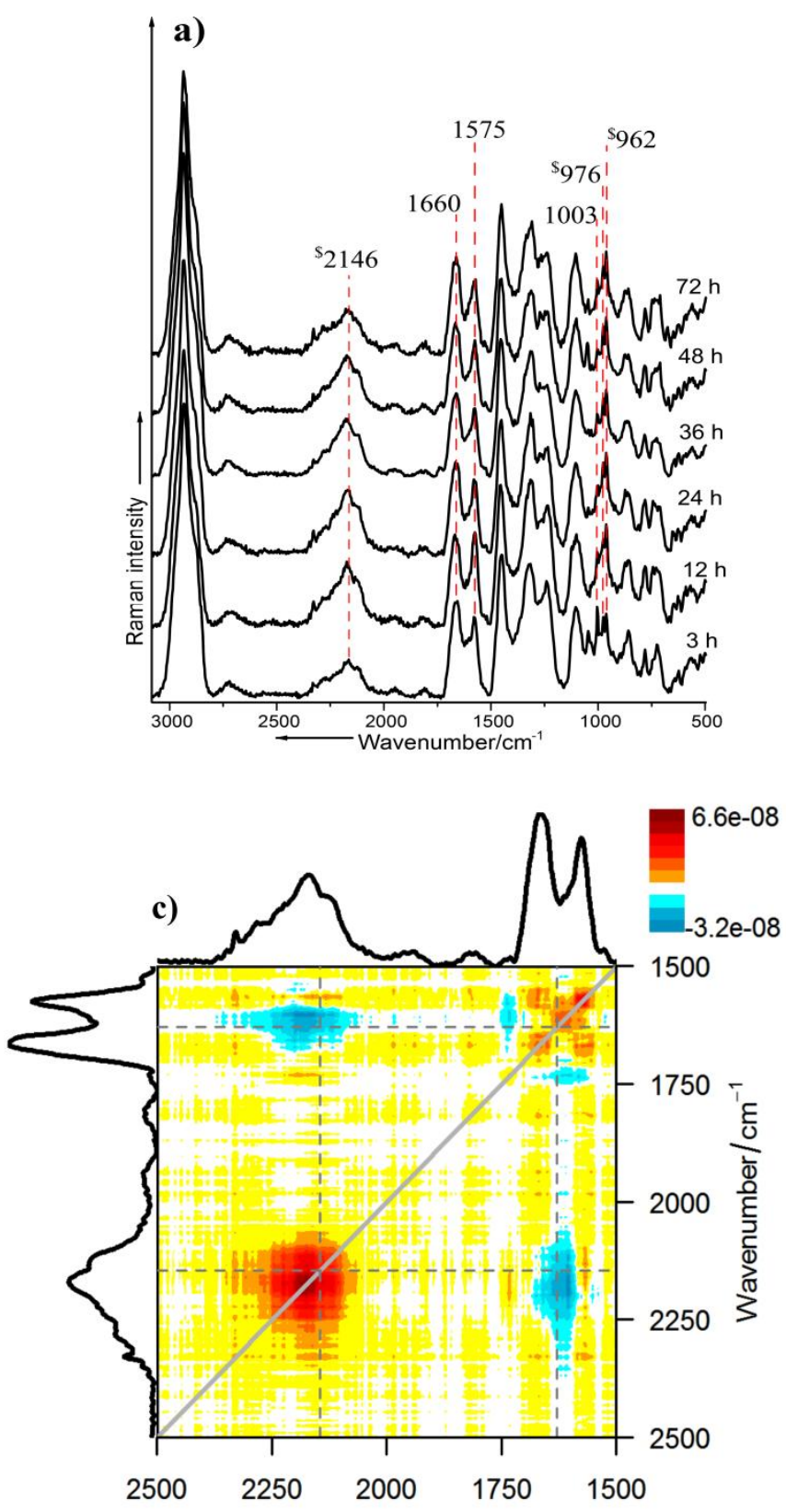

b)
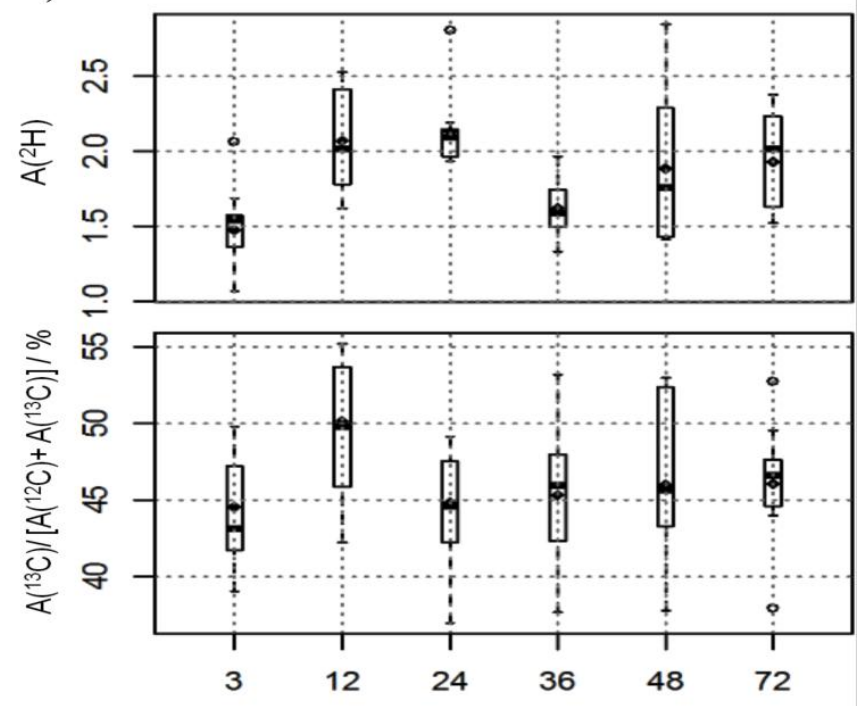

Time / h

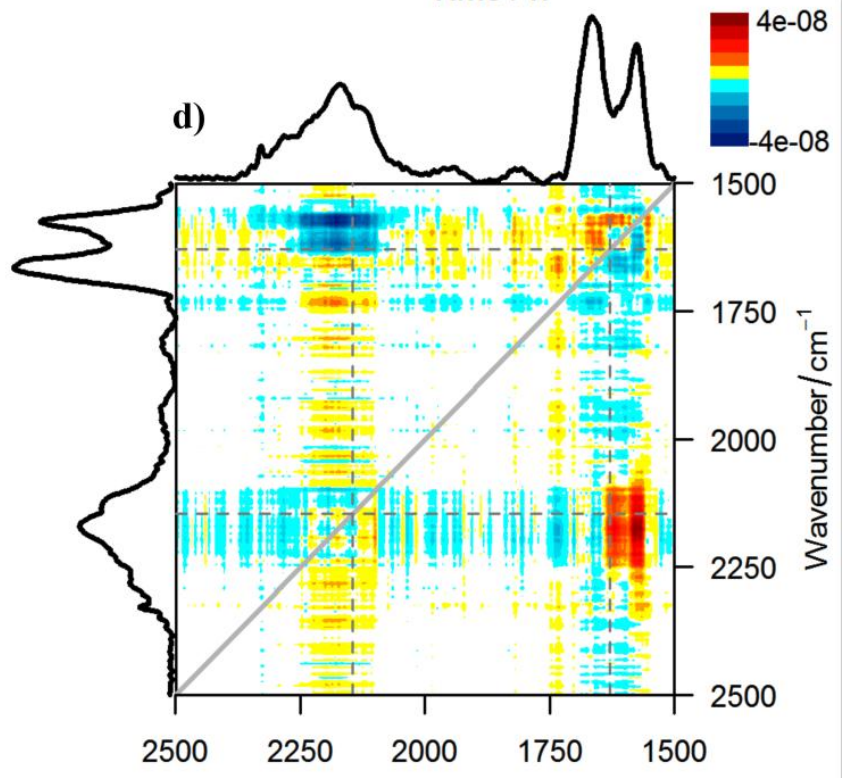

Wavenumber $/ \mathrm{cm}^{-1}$

Wavenumber $/ \mathrm{cm}^{-1}$

Figure S13. Visualization of carbon catabolite repression via ${ }^{2} \mathrm{H}$ and ${ }^{13} \mathrm{C}$ double labeling approach a) Time dependent spectra of $N$. aromaticivorans cultured with a combination of ${ }^{2} \mathrm{H}$ glucose and ${ }^{13} \mathrm{C}$ naphthalene as carbon sources, $(\$)$ indicates ${ }^{2} \mathrm{H}$ incorporation; At $3 \mathrm{~h}$, the predominant changes in the spectrum are due to the incorporation of ${ }^{2} \mathrm{H}$ isotope resulting from the utilization of glucose. During the course of $72 \mathrm{~h}$, these changes only showed a relatively small increase in intensity. However, there were no major changes observed indicating the incorporation of ${ }^{13} \mathrm{C}$ isotope due to utilization of naphthalene during the course of $72 \mathrm{~h} \mathrm{~b}$ ) $\mathrm{Ob}$ servation of the level of ${ }^{2} \mathrm{H}$ and ${ }^{13} \mathrm{C}$ isotope incorporation with the standard box plot showing population quartiles based on peak area calculations $\mathrm{A}\left({ }^{13} \mathrm{C}\right) /\left[\mathrm{A}\left({ }^{12} \mathrm{C}\right)+\mathrm{A}\left({ }^{13} \mathrm{C}\right)\right] \& \mathrm{~A}\left({ }^{2} \mathrm{H}\right)$; this plot indicates only a small relative increase in the uptake of ${ }^{2} \mathrm{H}$ is otope upto $12 \mathrm{~h}$ after which there is no major increase with time, this might be attributed to slow metabolic activity, and in comparison the box plot depicting ${ }^{13} \mathrm{C}$ incorporation shows only slight variation due to the changes in the $1660 \mathrm{~cm}^{-1}$ band resulting mostly from heterogeneous biomolecular distribution. c) Synchronous 2D Raman correlation spectrum; cons is ts of four autopeaks at 1575, 1627, 1660 and $2146 \mathrm{~cm}^{-1}$ indicating a change in these regions. The autopeak at $2146 \mathrm{~cm}^{-1}$ is strong while the former three are weak in intensity. This indicates a major change at $2146 \mathrm{~cm}^{-1}$ induced by ${ }^{2} \mathrm{H}$ incorporation from glucose whereas the minor changes in the other three regions can be attributed to relative intensity variation as explained previously. d) Asynchronous 2D Raman correlation spectrum of $N$. aromaticivorans $\left({ }^{2} \mathrm{H}\right.$ glucose $+{ }^{13} \mathrm{C}$ naphthalene) from 3 to $72 \mathrm{~h}$ in the spectral region from 1500 to $2500 \mathrm{~cm}^{-1}$ as obtained from the time dependent Raman spectra; as ynchronous spectrum shows a positive cross peak around coordinates $(1627,2146) \mathrm{cm}^{-1}$. The presence of a corresponding negative cross peak at these coordinates in the synchronous spectrum is also seen. This means that 
the spectral intensity change at $1627 \mathrm{~cm}^{-1}$ lags that at $2146 \mathrm{~cm}^{-1}$. As previously explained the changes due to heterogeneous molecular distribution are non sequential and in this case lags the changes occurring due to ${ }^{2} \mathrm{H}$ is otope uptake from the utilization of glucose. Importantly it is seen here that, no major changes were observed in the spectral pattern which indicated an incorporation of ${ }^{13} \mathrm{C}$ is otope due to the utilization of naphthalene during the course of $72 \mathrm{~h}$. These results clearly suggest that the utilization of naphthalene as an altemate carbon source is affected by CCR induced in the presence of glucose in this bacterium. 

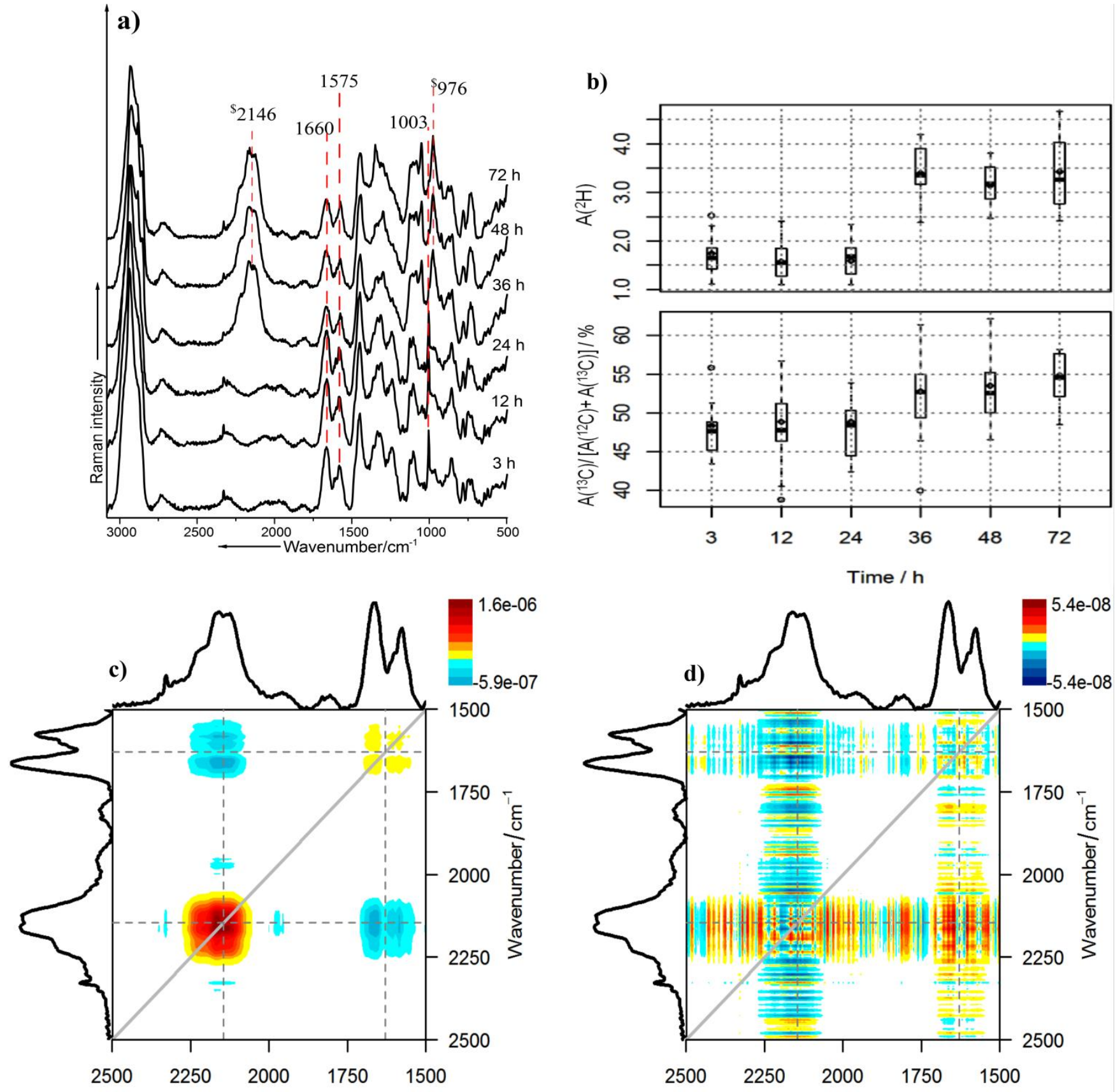

Wavenumber $/ \mathrm{cm}^{-1}$

Wavenumber $/ \mathrm{cm}^{-1}$

Figure S14. Visualization of carbon catabolite repression via ${ }^{2} \mathrm{H}$ and ${ }^{13} \mathrm{C}$ double labeling approach a) Time dependent spectra of C. basilensis cultured with a combination of ${ }^{2} \mathrm{H}$ glucose and ${ }^{13} \mathrm{C}$ galactose as carbon sources, (\$) indicates ${ }^{2} \mathrm{H}$ incorporation; It was previously mentioned that this bacterium is slow growing when compared to the other two species. It can be seen from the time dependent spectra that there is no incorporation of both ${ }^{13} \mathrm{C}$ and ${ }^{2} \mathrm{H}$ isotopes during the course of $24 \mathrm{~h}$ indicating very less metabolic activity. However, at $36 \mathrm{~h}$ the Raman bands corresponding to ${ }^{2} \mathrm{H}$ isotope incorporation predominantly appear attributable to the utilization of glucose. These signatures then only show little variation in increasing intensity during the remaining course of time running upto $72 \mathrm{~h}$. However, no prominent changes were detected during the course of $72 \mathrm{~h}$ to indicate ${ }^{13} \mathrm{C}$ incorporation resulting from the utilization of galactose b) Observation of the level of ${ }^{2} \mathrm{H}$ and ${ }^{13} \mathrm{C}$ isotope incorporation with the standard box plot showing population quartiles based on peak area calculations $\mathrm{A}\left({ }^{13} \mathrm{C}\right) /\left[\mathrm{A}\left({ }^{12} \mathrm{C}\right)+\mathrm{A}\left({ }^{13} \mathrm{C}\right)\right] \& \mathrm{~A}\left({ }^{2} \mathrm{H}\right)$; this plot indicates a prominent increase in the incomoration of ${ }^{2} \mathrm{H}$ is otope with time, and the box plot depicting ${ }^{13} \mathrm{C}$ incorporation is rather showing only slight variation during the course of $72 \mathrm{~h}$ resulting from the relative intensity changes in the $1660 \mathrm{~cm}^{-1}$ amide I band as mentioned previously c) Synchronous 2D Raman correlation spectrum; consists of three autopeaks at 1575, 1660 and $2146 \mathrm{~cm}^{-1}$ indicating changes in these regions. The autopeak at $2146 \mathrm{~cm}^{-1}$ is strong whereas the former two autopeaks are weak in intensity. This is due to the major 
change induced by the incorporation of ${ }^{2} \mathrm{H}$ is otope from glucose at $2146 \mathrm{~cm}^{-1}$ region and the minor changes are due to the relative intensity variation resulting from heterogeneous molecular distribution as seen in the time dependent spectra d) Asynchronous $2 \mathrm{D}$ Raman correlation spectrum of $C$. basilensis $\left({ }^{2} \mathrm{H}\right.$ glucose $+{ }^{13} \mathrm{C}$ galactose) from 3 to $72 \mathrm{~h}$ in the spectral region from 1500 to 2500 $\mathrm{cm}^{-1}$ as obtained from the time dependent Raman spectra; asynchronous spectrum shows a positive cross peak around the coordinates $(1660,2146) \mathrm{cm}^{-1}$. The presence of a corresponding negative cross peak around the same coordinates in the synchronous spectrum is also seen. This means that the spectral intensity change at $1660 \mathrm{~cm}^{-1}$ lags that at $2146 \mathrm{~cm}^{-1}$. As previously explained, these non sequential changes due to heterogeneous molecular distribution in some cas es lags the changes occurring due to ${ }^{2} \mathrm{H}$ isotope uptake from the utilization of glucose. Importantly it is seen here that, no major changes were observed in the spectral pattem which indicated an incorporation of ${ }^{13} \mathrm{C}$ is otope due to the utilization of galactose during the course of $72 \mathrm{~h}$. These results clearly suggest that the utilization of galactose as an altemate carbon source is affected by CCR induced in the presence of glucose in this bacterium. And also, its use may be affected by the reduced transport of galactose into the cells when compared to glucose as observed from the single labeling experiments. 


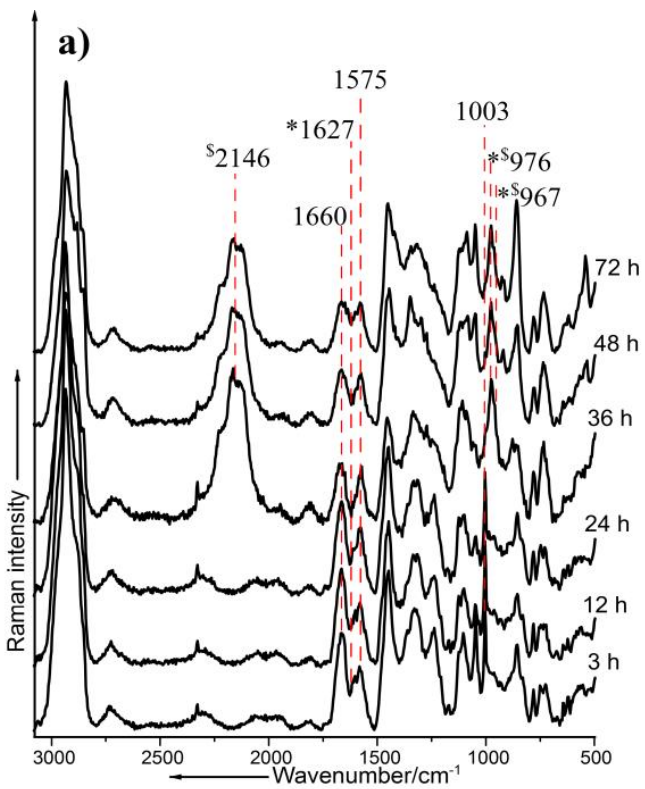

b)
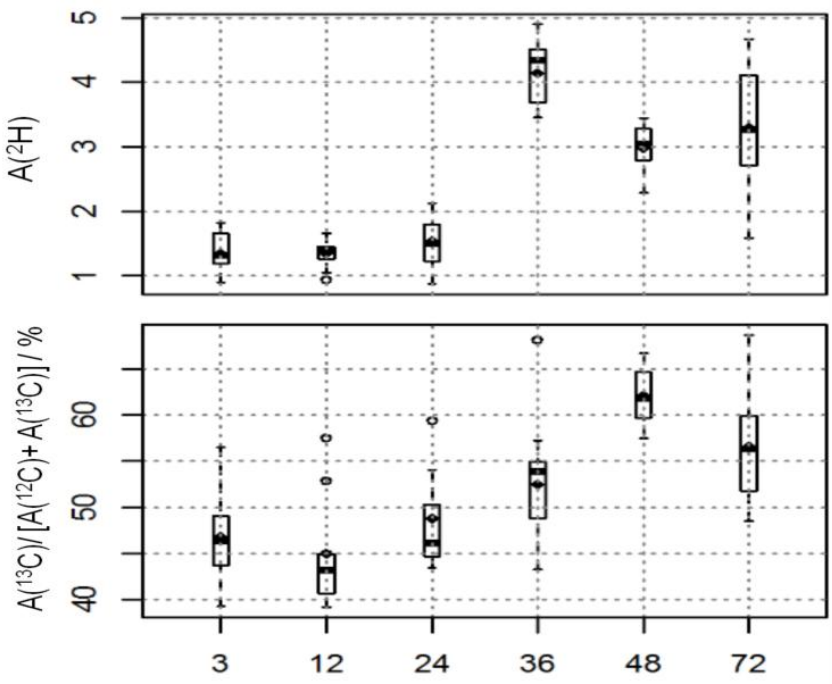

Time / h
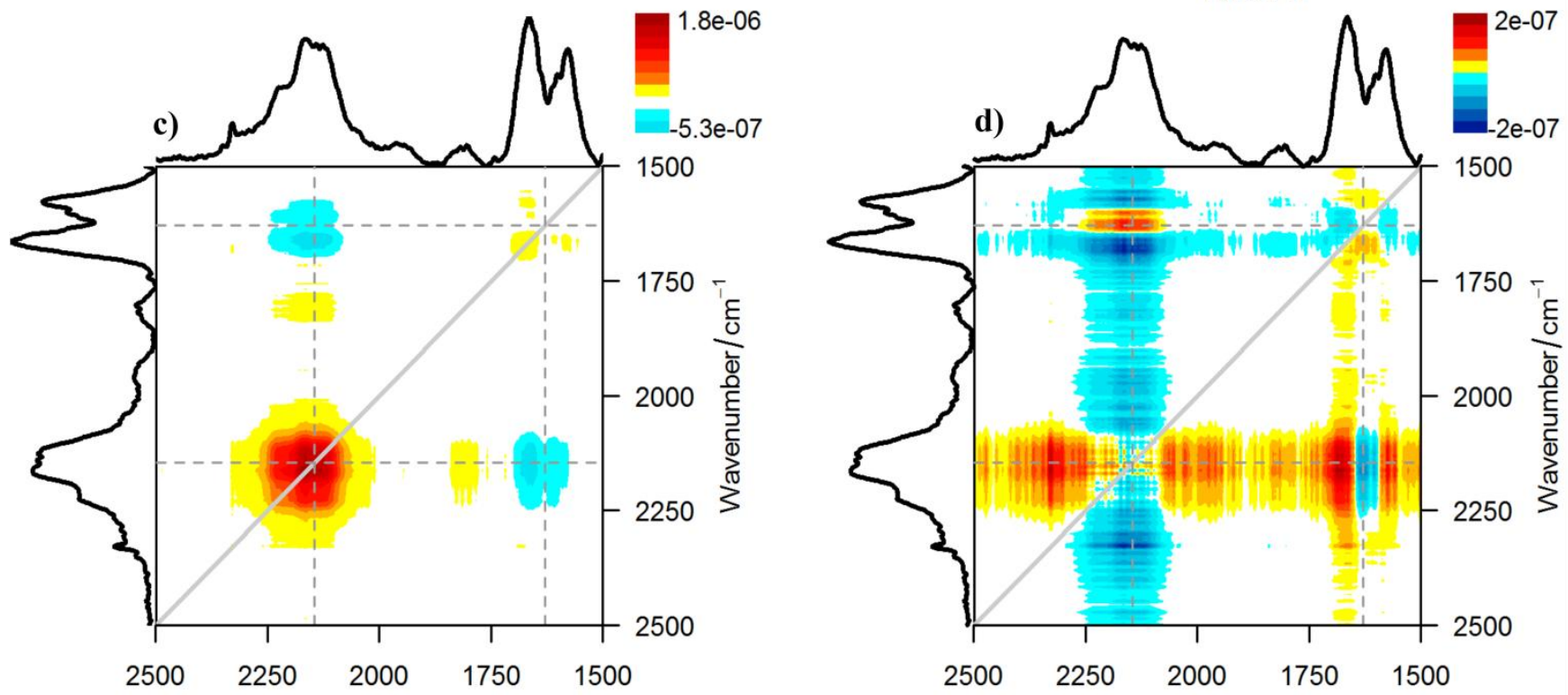

Wavenumber $/ \mathrm{cm}^{-1}$

Wavenumber $/ \mathrm{cm}^{-1}$

Figure S15. Visualization of carbon catabolite repression via ${ }^{2} \mathrm{H}$ and ${ }^{13} \mathrm{C}$ double labeling approach a) Time dependent spectra of C. basilensis cultured with a combination of ${ }^{2} \mathrm{H}$ glucose and ${ }^{13} \mathrm{C}$ fructose as carbon sources, (\$) indicates ${ }^{2} \mathrm{H}$ incorporation, $(*)$ indicates ${ }^{13} \mathrm{C}$ incorporation, $(* \$)$ indicates incorporation of both ${ }^{2} \mathrm{H}$ and ${ }^{13} \mathrm{C}$ is otope; it can be seen that at $36 \mathrm{~h}$ the Raman bands corresponding to ${ }^{2} \mathrm{H}$ isotope incorporation predominantly appear owing to the utilization of glucose. These signatures then only show little variation in increasing intensity during the remaining course of time running upto $72 \mathrm{~h}$. In contrast, only slight changes associated with the incorporation of ${ }^{13} \mathrm{C}$ due to the utilization of fructose were observed at $72 \mathrm{~h}$. There was a major decrease in the relative intensity of the Raman bands at $1660 \mathrm{~cm}^{-1}$ and $1575 \mathrm{~cm}^{-1}$ corresponding to amide I and nucleic acids at $72 \mathrm{~h}$ respectively. This indicated initiation of the amide I peak shift progression and superimposition over the nucleic acid band. These changes at $72 \mathrm{~h}$ suggested an incomporation of ${ }^{13} \mathrm{C}$ isotope from fructose albeit very minute when compared to ${ }^{2} \mathrm{H}$ incorporation b) Observation of the level of ${ }^{2} \mathrm{H}$ and ${ }^{13} \mathrm{C}$ isotope incorporation with the standard box plot showing population quartiles based on peak area calculations $\mathrm{A}\left({ }^{13} \mathrm{C}\right) /\left[\mathrm{A}\left({ }^{12} \mathrm{C}\right)+\mathrm{A}\left({ }^{13} \mathrm{C}\right)\right] \& \mathrm{~A}\left({ }^{2} \mathrm{H}\right)$; this plot indicates a prominent increase in the incoporation of ${ }^{2} \mathrm{H}$ isotope with time, and the box plot depicting ${ }^{13} \mathrm{C}$ incorporation is showing only a slight increase starting from $48 \mathrm{~h}$ c) Synchronous 2D Raman correlation spectrum; consists of two autopeaks at 1660 and $2146 \mathrm{~cm}^{-1}$ indicating changes in these regions. The autopeak at $2146 \mathrm{~cm}^{-1}$ is strong whereas the former autopeak is weak in intensity. This is due to the major change induced by the incorporation of ${ }^{2} \mathrm{H}$ isotope from glucose at $2146 \mathrm{c} \mathrm{m}^{-1}$ region and the minor changes at $1660 \mathrm{~cm}^{-1}$ are due to the slow uptake of ${ }^{13} \mathrm{C}$ isotope from fructose as also seen from the time dependent spectrum at $72 \mathrm{~h} \mathrm{~d}$ ) Asynchronous 2D Raman correlation spectrum of C. basilensis $\left({ }^{2} \mathrm{H}\right.$ glucose $+{ }^{13} \mathrm{C}$ galactose) from 3 to $72 \mathrm{~h}$ in the spectral region from 1500 to $2500 \mathrm{~cm}^{-1}$ as obtained from the time dependent Raman spectra; asynchronous spectrum shows positive cross peaks around the coordinates $(1575,2146) \mathrm{cm}^{-1}$ and $(1660,2146) \mathrm{cm}^{-1}$. Also a negative cross peak at coordinate $(1627,2146) \mathrm{cm}^{-1}$ can be seen. This pattem as observed previously might be indicating the progression of peak shift of the amide I band at 1660 towards $1627 \mathrm{~cm}^{-1}$ and the subsequent superimposition of the nucleic acid band at $1575 \mathrm{~cm}^{-1}$. 
These changes are minute and hence not observed very clearly in the time dependent spectra which highlights the significance of the 2D Raman correlation spectrum. As seen, the sign of the asynchronous cross peak around the coordinates $(1660,2146) \mathrm{cm}^{-1}$ is positive but the corresponding synchronous cross peak at the same position is negative. This means that the spectral intensity change at $1660 \mathrm{~cm}^{-1}$ lags that at $2146 \mathrm{~cm}^{-1}$. These results indicate a faster utilization of glucose over fructose. Nevertheless, it is seen here that the pattern of changes observed in the time dependent and asynchronous Raman spectrum indicated an incorporation of ${ }^{13} \mathrm{C}$ is otope from the utilization of fructose. The percentage of incorporation is obviously very minute and seems to be masked by the predominant incorporation of ${ }^{2} \mathrm{H}$ is otope from the utilization of glucose as seen in the time dependent spectra at $72 \mathrm{~h}$. These results suggest that fructose can be cometabolized along with glucose in this bacterium. However, glucose is utilized at a much faster rate when compared to fructose if they are provided in combination as carbon sources to this bacterium. 